\title{
Prostate Cancer, Update of its Diagnosis and Treatment, with Special Emphasis on its Management in Argentina
}

\section{Adrian Pablo Hunis ${ }^{1 *}$ and Melisa Hunis ${ }^{2}$}

${ }^{1}$ Assistant Professor of Internal Medicine, University of Buenos Aires, Argentina

${ }^{2}$ Head Professor of Oncology, Maimonides University, Argentina

Submission: December 02, 2020; Published: December 22, 2020

*Corresponding author: Adrian Pablo Hunis, Assistant Professor of Internal Medicine, University of Buenos Aires, Argentina

\section{Abstract}

Prostate cancer is the second most frequent tumor in men in Argentina. Since the work of Charles Huggins, in 1941, in which he demonstrates that the suppression of the male sex hormone-testosterone-through surgical castration, many years have passed and many advances have been made in terms of diagnosis and treatment of this disease, paradigm of a hormone-dependent tumor. In this work, we intend to summarize the advances and the problems of the disease in the Argentine Republic.

Keywords: Prostate; Prostate cancer; Castration; Hormonal treatments

\section{Introduction}

Prostate carcinoma is one of the most frequent tumors in Argentina. As incident cases grouped expressed in percentages,

the prostate represents $9 \%$ of new case in the country (GLOBOCAN 2018;) (Figure 1).

\section{Argentina
Source: Globocan 20}

Number of new cases in 2018, both sexes, all ages

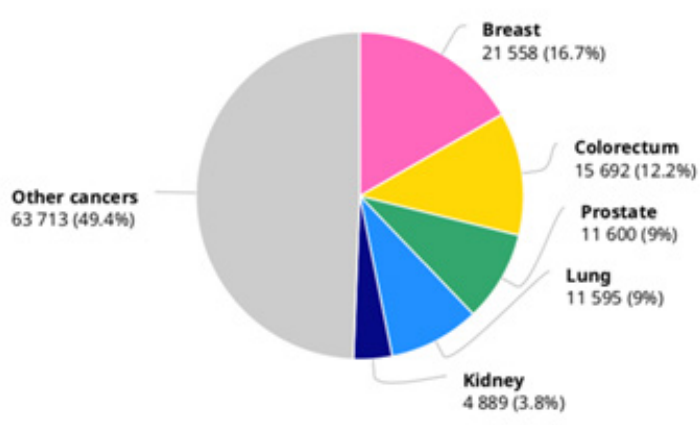

Total: 129047

Figure 1: Globocan 2018 


\section{Cancer Therapy \& Oncology International Journal}

Its racial incidence varies significantly, Africans living in the United States have the highest incidence in the world (224 cases per 100,000) (Figure 2). The incidence in African Americans is highly higher than that of White Americans (150 per 100,000), Western Europeans (39.6 per 100,000), Japanese (8.5 per 100,000), and Chinese (1.1 per 100,000). (Figure 3).

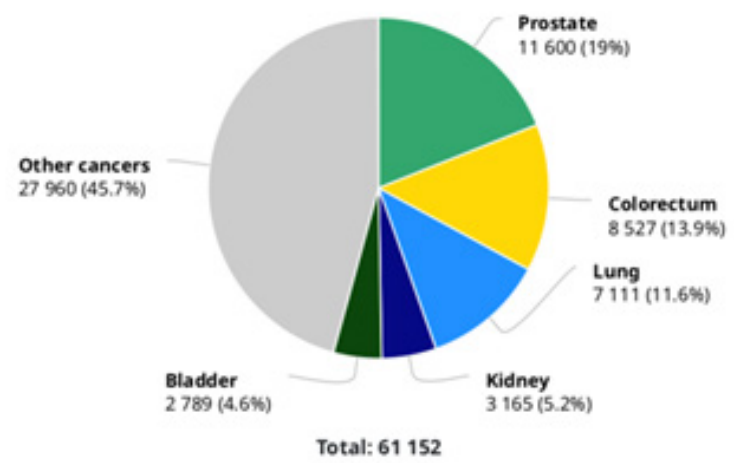

Figure 2: number of new cases in (2018) in males, all ages is $19 \%$.
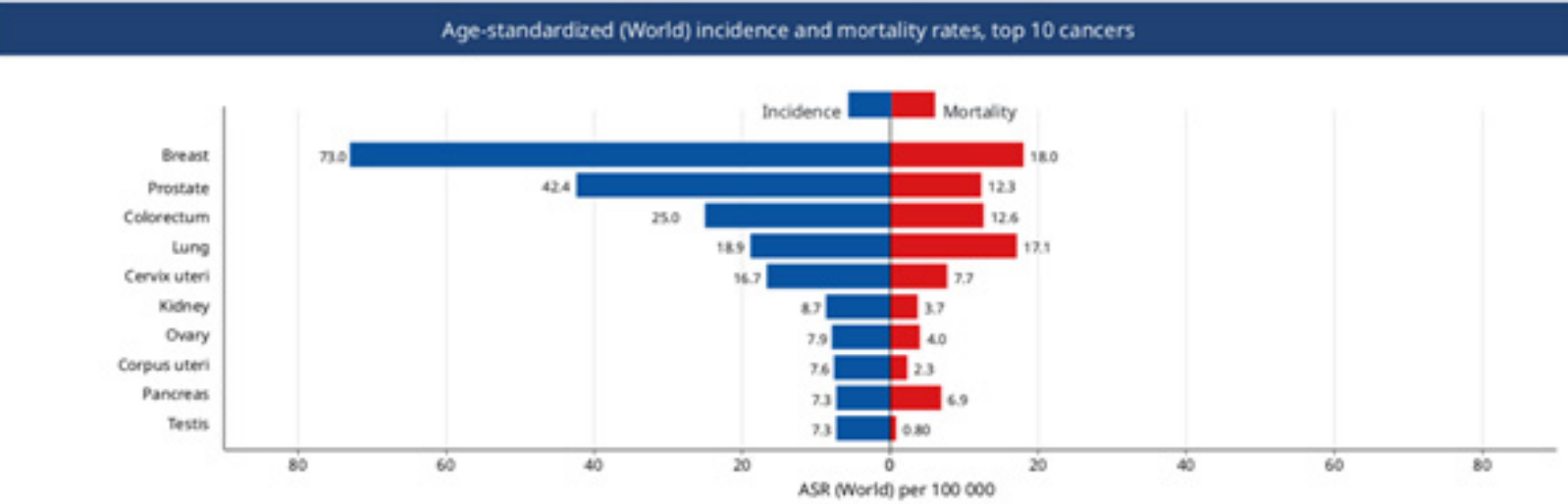

Figure 3: The incidence in African Americans is highly higher than that of White Americans (150 per 100,000), Western Europeans (39.6 per 100,000), Japanese (8.5 per 100,000), and Chinese (1.1 per 100,000).

Through the last half of the twentieth century, the annual incidence of prostate cancer increased slowly but steadily, probably due to an increase in life expectancy and hence an increase in the population of men of susceptible age (older than 50 years). Other factors have also contributed, such as the introduction and widespread use of PSA (prostate specific antigen) measured in blood. The PSA identifies a large number of asymptomatic patients with prostatic carcinoma, the so-called prevalent cases [1-10].

\section{Associated Risk Factors}

The etiology of prostate cancer is not known. But associated risk factors are known such as: family history, age, race, diet, hormonal levels. The more advanced the age, the more possibility there is of suffering from this pathology. Analyzed the process at a cellular level, however, the onset of prostate cancer is an early process, it has been detected in autopsies in the prostates of men of 20 and 30 years of age. Thus, prostate cancer is defined as small, microscopic amounts of low-grade carcinoma, found incidentally in the prostate.

In one study, $20 \%$ of men younger than 40 had histological evidence of prostate cancer.

In contrast, clinically detected prostate cancer at age 40 is rare. The prevalence of both latency and clinically detected cancer increases significantly with age: 20 to $30 \%$ of men over 50 years of age and probably $50 \%$ of men over 80 years of age may have prostate cancer. The majority of clinically detected prostate tumors are in the seventh and eighth decade of life. The 


\section{Cancer Therapy \& Oncology International Journal}

relationship between latent and clinically detectable is uncertain. It is not known whether they represent two different entities, or whether latent prostate cancer is a clinically detectable precursor to cancer. Other determining risk factors in prostate cancer are race and geographic origin. As we saw earlier, African Americans have the highest incidence. In contrast, the lowest incidence rates are found in Japan and China. As in other tumors, when members of a racial community move from regions of low incidence to regions of high incidence, the incidence of prostate cancer increases in that group. However, genetic factors can be operative as well. For example, the gene for the androgen receptor (encoded on the $\mathrm{X}$ chromosome) contains a repeating polymorphic CAG sequence. Several studies indicate that individuals with fewer repeated CAG sequences in the androgen receptor genes have a higher risk of developing prostate cancer. In African Americans, fewer CAG repeat sequences were found than in Hispanics and Asians. Thus, part of the high incidence of this pathology in African Americans may be due to this phenomenon. Family history is related to prostate cancer. The risk increases with the number of affected relatives. Vasectomy increases the risk of prostate cancer. The relationship between diet and prostate cancer is probably very important, although it is difficult to prove given that the data come mostly from epidemiological studies, rather than prospective studies. But diet could contribute to the dramatic difference between western and eastern countries. Important studies maintain that the content of red meat, animal fat and its high level of consumption increases the risk. Other factors such as lycopene, a carotenoid found in tomatoes, lower the risk. Among the micronutrients and trace elements, selenium, vitamin E, soy and vitamin D can lower the risk. Other risk factors are exposure to cadmium: welding, batteries or electrotypes [11-20].

\section{Molecular Biology}

Prostate cancer is a heterogeneous and complex disease that results from a series of genetic events at the level of the epithelial prostate cell. These genetic events and many of the environmental factors that promote tumor development or progression are still poorly defined. A small group of prostate tumors may derive from the inheritance of one of several important genes that predispose to the malignant phenotype and, therefore, confer a high risk of prostate cancer [21-30].

Familial prostate cancer constitutes an estimated $5-10 \%$ of all prostate cancers and probably as much as $50 \%$ of prostate cancers in men under 55 years of age. Six candidate loci for familial prostate cancer have been identified; the gene at one of these loci, HPC-1 (hereditary prostate cancer-1), has been found to be ribonuclease $\mathrm{L}$ (RNase L). The relationship with HPC-1 could be associated with a more malignant tumor phenotype. Several genes that participate in the regulation of the cell cycle and in the regulation of growth factor signaling (Rb, p53, and PTEN), have been implicated in the development and progression of prostate cancer. The prevalence of mutations in these genes has varied from study to study, and the role that genes play in the development and progression of prostate cancer has yet to be defined. Also, a variety of proto-oncogenes have been implicated in the bio pathogenesis of this tumor [31-40].

Although there is strong evidence of a dysregulation of a variety of growth factors (IGF-1, EGF, PDGF, etc.), also as receptors to them (Her-2 / neu, receptor to EGF and TGF beta) their exact roles are not well understood yet. (Figure 4).

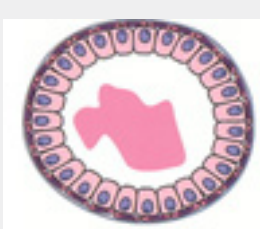

Normal
epithelium

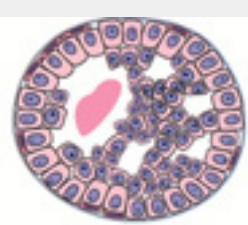

Prostatic intraepithelial
neoplasia (PIN)

Loss of basal cells

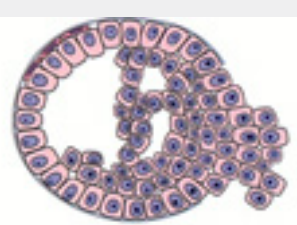

Invasive carcinoma

Loss of basal lamina

Loss of 17p p53

Figure 4: Several genes that participate in the regulation of the cell cycle and in the regulation of growth factor signaling (Rb, p53, and PTEN), have been implicated in the development and progression of prostate cancer. 


\section{Cancer Therapy \& Oncology International Journal}

\section{Screening of Prostate Cancer}

The purpose of screening for prostate cancer is to detect tumor within the gland, potentially curable by definitive local therapeutics. Historically, the investigation was performed by digital rectal examination. But, due to the great variations that exist with the latter, many tumors are not palpable, and most of the tumors detectable by digital rectal examination are not confined to the prostate and therefore are not curable. Today screening is carried out with the measurement of prostate specific antigen (PSA) in the blood, which greatly increases the detection of disease confined to the gland.

PSA is a member of the kallikrein family, chemically a glycoprotein with serine protease activity. It is abundant in semen, where it is responsible for dissolving the seminal clot. PSA is produced by both normal and malignant prostate epithelial cells; production is higher in normal cells. Therefore, conditions such as benign prostatic hyperplasia, acute prostatitis, elevate PSA levels. When prostate cancer develops, the serum PSA level is frequently elevated due to the absolute increase in epithelial cell volume and possibly the passage of PSA from tissue to serum. Optimal screening for prostate cancer combines the use of the PSA test and digital rectal examination. This is because most tumors are not palpable, and some do not produce enough PSA to increase the level of serum PSA. PSA test determination can detect prostate cancer an average of 5.5 years before clinical detection becomes evident. Most of the tumors detected today by PSA are non-palpable, asymptomatic tumors that are potentially curable. The American Cancer Society currently recommends digital rectal exams and PSA annually for men over 50 years of age who have a life expectancy greater than 10 years. For the high-risk group (African American, patient with a family history of prostate cancer), screening is recommended to start at 40 years of age. Some troublesome topics, however, exist with PSA testing. Detection of clinically insignificant tumors can lead to unnecessary treatment for many men. Also, an elevated PSA lacks specificity [41-50].

Despite the possibility of prostate cancer in men with moderately elevated PSA levels (4 to $10 \mathrm{ng} / \mathrm{ml}$ ), biopsy in these cases usually demonstrates benign prostatic hyperplasia rather than prostate cancer. On the other hand, the majority of cases with serum PSA levels above 10ng / $\mathrm{ml}$ present with prostate cancer, and their tumors are surely already outside the prostate gland. The percentage free PSA coefficient is a blood test that measures the amount of PSA that circulates alone (unconjugated) in the blood and the amount that is conjugated to other plasma proteins [51-60].

If the PSA test results are marginal and the percentage ratio of free PSA is low ( $25 \%$ or less), then it is more likely that we are in the presence of prostate cancer. If the results of the percentage free PSA coefficient are normal, even with a marginal PSA result, the biopsy may be avoided. PSA levels increase with age, and the use of specific PSA levels adjusted to the same age can increase the sensitivity of screening for prostate cancer in young people and increase the specificity of an elevated serum PSA in the elderly. This strategy is particularly important in young people, in whom prostate cancer is generally fatal [61-70].

\section{Diagnosis}

Prostate biopsy is generally performed when a tumor is suspected by elevated serum PSA, an abnormal rectal examination, or both. Biopsies are performed transrectally (Figure 5). A transrectal ultrasound device is inserted into the rectum to view the prostate during the biopsy. Traditionally, prostate biopsies are taken in a six-part pattern: bilaterally at the base, in the middle of the gland, and at the apex. The differential diagnoses with prostate cancer are: benign hyperplasia, chronic prostatitis, prostatic lithiasis, TB, granulomatosis, prostatic infarction and some bladder tumors [71-80].

Figure 5: Transrectal ultrasound device is inserted into the rectum to view the prostate during the biopsy. 


\section{Cancer Therapy \& Oncology International Journal}

\section{Pathological Anatomy}

Most prostate tumors are adenocarcinomas; Small cell carcinomas and sarcomas may also occasionally be seen. Adenocarcinomas arise from the glandular epithelium of the prostate and are frequently multifocal. The diagnosis is frequently made on the basis of a small portion of glandular material in relation to the limitations in taking biopsy of it. One of the changes towards carcinoma is the loss of the basal layer within the glandular epithelium. Invasion into the surrounding stroma is common and makes diagnosis easier. In 1966, Dr. Donald F. Gleason published a systematic classification for grading the pathological features of prostate cancer. This system is based on the degree of glandular differentiation of the tumor in which 5 patterns from 1 to 5 are taken into account that go from the degrees of least aggressiveness to the greatest, where the score or combined Gleason pattern is obtained from the sum of predominant patterns in the tumor [8190].

In 1993, the WHO recommended the preferential use of the Gleason classification in the pathology report referring to a diagnosis of prostate cancer. In 2005, during a Conference of the International Society of Urologic Pathology (ISUP), a substantial modification of the Gleason grading system was approved. The most important changes were related to morphological criteria to include poorly differentiated glands as a Gleason pattern 4, and stricter criteria to distinguish the cribriform pattern 4 from the cribriform pattern 3; as well as recommendations on how to grade the different variants of prostate cancer and how to report the Gleason grade in prostate biopsy and radical prostatectomy
[91-100].

The conference concluded with some controversial issues related to morphology, which remained pending resolution. The lack of consensus on certain grading problems, advances in research and changes in the clinical management of prostate cancer made evident the need to provide solutions. In 2013, Dr. Jonathan I. Epstein from Johns Hopkins University (JHU) led a classification proposal in the US that described grades of prognostic groups (GG1 to GG5) based on biochemical recurrence, based on a study of 7869 patients treated by radical prostatectomy at Johns Hopkins Hospital in Baltimore, between 1982 and 2011, with a mean follow-up of 2 years (range: 1-8 years). The biochemical recurrence at 5 years was 95\%,83\%, 65\%, 63\% and 34\% in men with a GG1 to GG5, respectively in biopsy, and 97\%, 88\%, 70\%, $64 \%$ and $34 \%$ for GG1 to GG5 in radical prostatectomy [101-110].

In 2014, ISUP organized a new consensus conference in Chicago with the participation of 67 prostate cancer expert pathologists from 17 countries, and 17 clinicians, including urologists, radiation oncologists and medical oncologists where this study was discussed and approved by consensus the new classification of degrees of prognostic groups. At this conference, various proposals to update the Gleason scale were also approved, including the assignment of a Gleason 4 pattern to all cribriform glands and glomeruloid structures, the grading of mucinous carcinoma based on the underlying growth pattern. The nongrading of intraductal carcinoma, the recommendation to report the percentage of pattern 4 in the Gleason score 7 and the noncommunication of the tertiary pattern in the prostate biopsy [111-126].

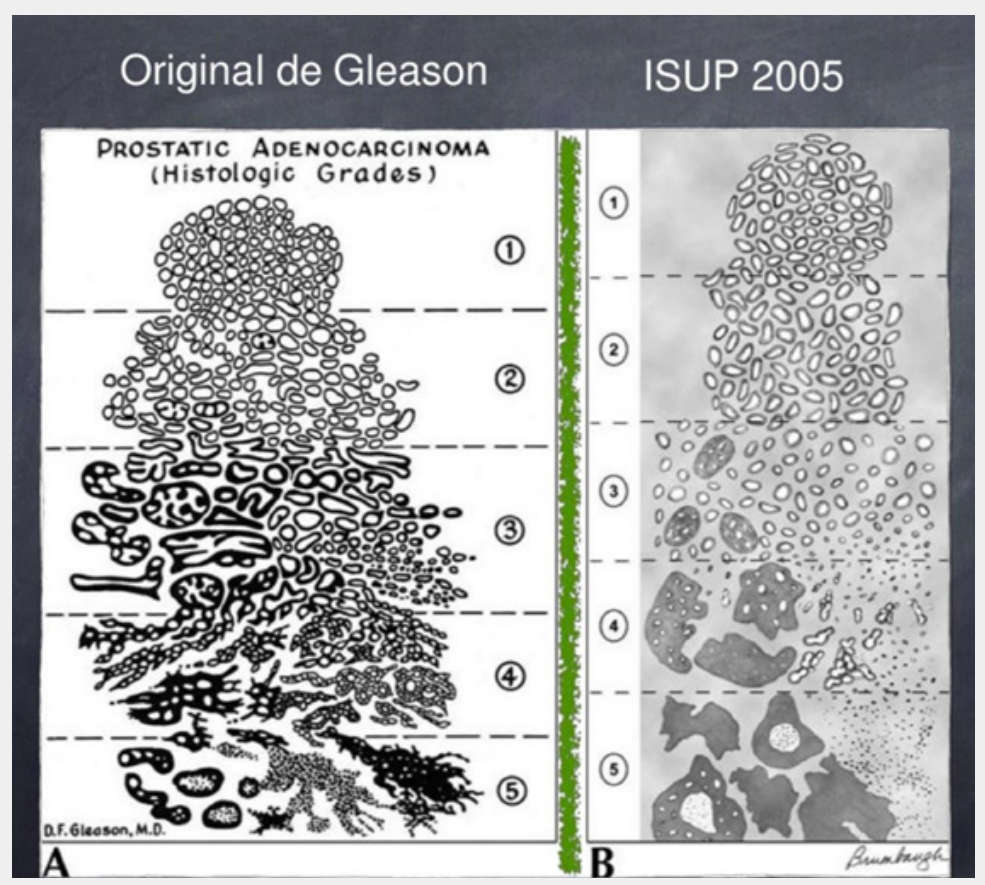

Figure 6: Prostatic Adenocarcinoma (Histologic Grades). 


\section{Cancer Therapy \& Oncology International Journal}

The final nomenclature for this classification remains to be approved. Currently, JHU and ISUP have a dispute over this. Johns Hopkins defends the term "Prognostic Group Grades" and the ISUP defends the nomenclature "ISUP Grades". (Figure 6). The new prognostic group grade classification will help pathologists improve the classification of prostate cancer based on glandular morphology. It will also be of use to other clinicians, researchers, and patients, as it has a better correlation with current disease management, including active surveillance of patients with lowgrade cancer.

Prognostic group grade translation should be fairly straightforward as it is based on Gleason scores. It is expected that in the next one or two years, after a period in which cancers are reported with the old and updated systems, and the institutional and national databases are adapted, this classification will be accepted and used regularly in the clinical practice.

\section{Early Clinical Presentation}

The initial symptoms that occur in prostate cancer are: difficulty starting or finishing urination, reduced force in the urine stream, dripping at the end of urination, painful or burning urination, nocturia, painful ejaculation, hematuria. As we can see, most of these signs and symptoms may well be found in benign pathologies of the prostate.

\section{Late Clinical Presentation}

Late symptoms in prostate cancer are anemia, uremia, bone pain (due to bone metastases), hydronephrosis, weight loss, neurological deficit in the lower limbs (spinal cord compression), coagulation disorders, hypoalbuminemia. Of these, the minor symptoms that mark the need for treatment in the patient are anemia, hypoalbuminemia, and weight loss.

\section{STAGING (TNM)}

Definitions

\section{Primary Tumor (T)}

CLINICAL

TX Primary tumor cannot be assessed

T0 No evidence of primary tumor

T1 Clinically inapparent tumor neither palpable nor visible by imaging

T1a Tumor incidental histologic finding in $5 \%$ or less of tissue resected

T1b Tumor incidental histologic finding in more than 5\% of tissue resected

T1c Tumor identified by needle biopsy (for example, because of elevated PSA)

T2 Tumor confined within prostate T2a Tumor involves onehalf of one lobe or less

T2b Tumor involves more than one-half of one lobe but not both lobes

T2c Tumor involves both lobes T3 Tumor extends through

the prostate capsule

T3a Extracapsular extension (unilateral or bilateral)

T3b Tumor invades seminal vesicle(s)

T4 Tumor is fixed or invades adjacent structures other than seminal vesicles, such as external sphincter, rectum, bladder, levator muscles, and/or pelvic wall (Figure 7)

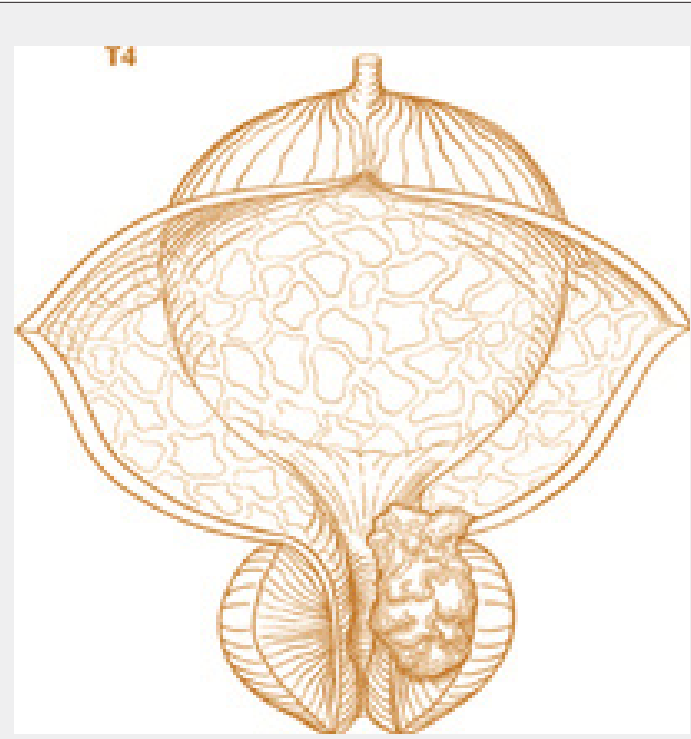

Figure 7: T4 tumor invading adjacent structures other than seminal vesicles, such as bladder, rectum, levator muscles, and/or pelvic wall. 


\section{Cancer Therapy \& Oncology International Journal}

\section{Pathologic (pT)}

pT2 Organ confined

pT2a Unilateral, one-half of

one side or less

pT2b Unilateral, involving more than one-half of side but not both sides

\section{pT2c Bilateral disease}

pT3 Extraprostatic extension

pT3a Extraprostatic extension or microscopic invasion

of bladder neck

pT3b Seminal vesicle invasion

pT4 Invasion of rectum, levator muscles, and/or pelvic wall

\section{Regional Lymph Nodes (N)}

Clinical

NX Regional lymph nodes were not assessed

N0 No regional lymph node metastasis

N1 Metastasis in regional lymph node(s)

\section{Pathologic}

pNX Regional nodes not sampled pN0 No positive regional nodes pN1 Metastases in regional node(s).

\section{Distant Metastasis (M)}

a) M0 No distant metastasis

b) M1 Distant metastasis

a) M1a Nonregional lymph node(s)

b) M1b Bone(s)

c) M1c Other site(s) with or without bone disease

a) 1 Tumor found in one or both lobes by needle biopsy, but not palpable or reliably visible by imaging, is classified as T1c.

b) 2 Invasion into the prostatic apex or into (but not beyond) the prostatic capsule is classified not as T3 but as T2.

c) 3 There is no pathologic T1 classification.

d) 4 Positive surgical margins should be indicated by an R1

e) descriptor (residual microscopic disease).

f) 5 When more than one site of metastasis is present, the most advanced category is used. pM1c is most advanced.

g) 6 When either PSA or Gleason is not available, grouping should be determined by T stage and/or either PSA or Gleason as available.
Staging in prostate cancer attempts to determine which tumors are confined to the gland (and are thus curable by local maneuvers only) and which are not. Prostate cancer spreads to lymph nodes and bone. Spread to the liver and lung is clinically more unusual. The staging scheme currently used is as follows: Table 1

Table 1: $7^{\text {th }}$ Edition Staging Posters provided by the American Cancer Society.

\begin{tabular}{|c|c|c|c|c|c|}
\hline Group & $\mathbf{T}$ & $\mathbf{N}$ & M & PSA & Gleason \\
\hline \multirow{3}{*}{ I } & T1a-c & No & M0 & $\mathrm{PSA}<10$ & Gleason $\leq 6$ \\
\hline & T2a & No & M0 & $\mathrm{PSA}<10$ & Gleason $\leq 6$ \\
\hline & $\mathrm{T} 1-2 \mathrm{a}$ & No & M0 & PSA X & Gleason X \\
\hline \multirow{6}{*}{ IIA } & T1a-c & No & M0 & $\mathrm{PSA}<20$ & Gleason 7 \\
\hline & T1a-c & No & M0 & $P S A \geq 10<20$ & Gleason $\leq 6$ \\
\hline & $\mathrm{T} 2 \mathrm{a}$ & N0 & M0 & $P S A \geq 10<20$ & Gleason $\leq 6$ \\
\hline & $\mathrm{T} 2 \mathrm{a}$ & N0 & M0 & $\mathrm{PSA}<20$ & Gleason 7 \\
\hline & $\mathrm{T} 2 \mathrm{~b}$ & No & M0 & $\mathrm{PSA}<20$ & Gleason $\leq 7$ \\
\hline & $\mathrm{T} 2 \mathrm{~b}$ & No & M0 & PSA X & Gleason X \\
\hline \multirow{3}{*}{ IIB } & $\mathrm{T} 2 \mathrm{c}$ & N0 & M0 & Any PSA & Any Gleason \\
\hline & T1-2 & N0 & M0 & $P S A \geq 20$ & Any Gleason \\
\hline & T1-2 & No & M0 & Any PSA & Gleason $\geq 8$ \\
\hline III & T3a-b & N0 & M0 & Any PSA & Any Gleason \\
\hline \multirow{3}{*}{ IV } & $\mathrm{T} 4$ & No & M0 & Any PSA & Any Gleason \\
\hline & Any $\mathrm{T}$ & N1 & M0 & Any PSA & Any Gleason \\
\hline & Any $\mathrm{T}$ & Any N1 & M1 & Any PSA & Any Gleason \\
\hline
\end{tabular}

\section{Diagnosis by Images}

The iconographic studies are of great importance in the patient with prostate cancer. If these are performed to stage the patient, there they manifest their importance. If, on the other hand, the patient has advanced disease, they will allow us to evaluate the response to treatment. In the first case, every patient should have a chest X-ray ( $\mathrm{f}$ and P), a liver ultrasound, and fundamentally a whole-body bone scan to evaluate the first metastatic site, which is the bone (Figure 8).

\section{Magnetic Resonance Imaging (MRI)}

(Figure 9) A few years ago, the diagnosis of prostate cancer was based on screening with prostate-specific antigen (PSA), which has been used and is used massively until now. On the other hand, randomized biopsy is the method used to access samples for histological study. This has led to over-diagnosis and overtreatment of non-clinically significant lesions (NSC), that is, they will never produce metastasis and will not put the patient's life at risk.

The over-treatment of these indolent cancers can also generate a detriment in the quality of life due to intestinal, urinary and erectile dysfunctions. In order to avoid over-treatment, these 


\section{Cancer Therapy \& Oncology International Journal}

patients began to follow active surveillance protocols. However, some of them also presented clinically significant lesions (CS) hidden in places of lesser scope for randomized biopsy, such as the anterior region of the prostate - that located before the urethra - and the prostatic apex, and therefore showed an unfavorable natural evolution, even with the appearance of metastasis. It is worth remembering that all those with a Gleason score of 7 or higher are considered CS cancers. This is how another diagnostic method became necessary that had the ability to diagnose only CS lesions.

\section{Multiparametric MRI of the Prostate}
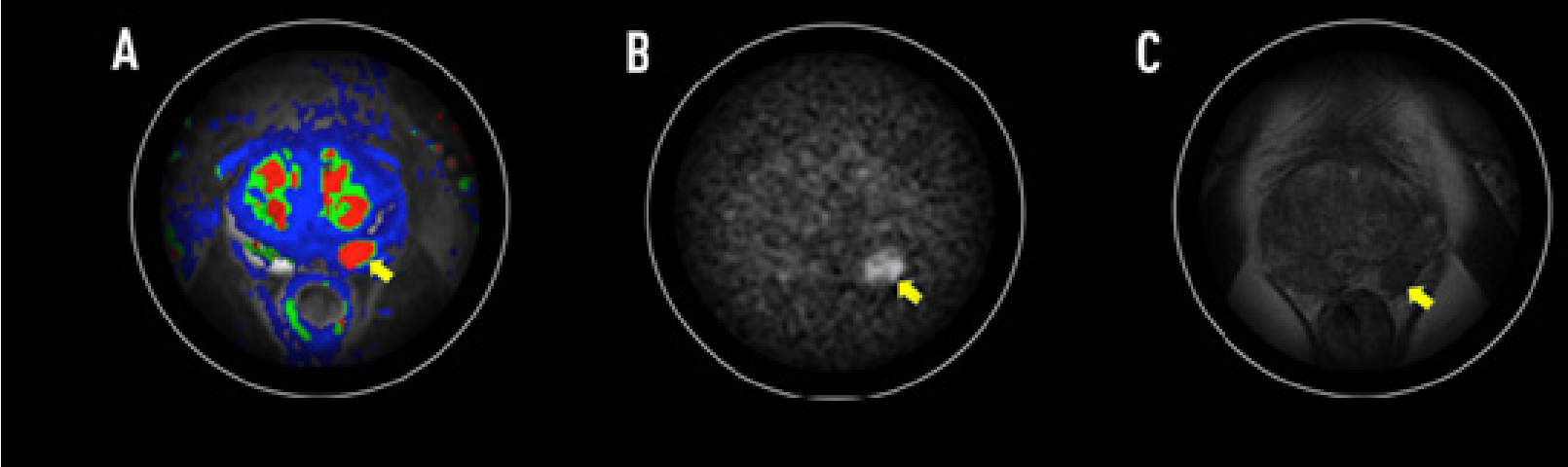

Figure 9: Magnetic Resonance Imaging (MRI).

The use of magnetic resonance imaging (MRI) of the prostate dates back to the 1980s, but its main development began around 2007, when articles began to appear with the use of diffusion in the study of the prostate2,3. Spectroscopy had begun to develop a little earlier. In 2011 the European Society for Urogenital Radiology (ESUR) proposed the "Prostate Imaging-Reporting and Data System version 1" (Pi-RADS v1). In 2014, the "Prostate
Imaging-Reporting and Data System version 2" (PI-RADS v2)4 was released, designed jointly by the American College of Radiology, ESUR, and the Ad MeTech Foundation, with the aim of improving the detection and characterization of prostate cancers through MRI, systematizing the multiparametric MRI (MRI-mp) technique of the prostate, and also simplifying and systematizing the reporting of these exams. 
After the publication of PI-RADS 2, multiple studies have been published and some limitations and ambiguities were identified that are attempted to be resolved with the version 2.1 recently published in March of this year5.

\section{MRI-mp prostate technique}

Prostate MRI-mp requires high-resolution T2-weighted anatomical sequences, in addition to functional diffusion sequences (DWI) and contrasting dynamic sequences (DCE). The T1-weighted sequences are also aggregated to investigate blood content, nodal and bone metastases. In PI-RADS v2 a sequence considered dominant for the peripheral zone (DWI sequence) and a dominant sequence for the transition zone (T2-weighted sequence) are proposed.

The PI-RADS v2 also details the minimum technical requirements needed for an adequate MRI-mp. In a 20186 article, Steven and others studied the adherence of 107 establishments to the technical parameters of the PI-RADS v2, demonstrating a wide range of adherence from 20 to $100 \%$ for individual acquisition parameters, concluding that even greater dissemination of these minimum standards is necessary. It is not the objective of this text to individualize them, but some points of the functional sequences will be discussed:

\section{Diffusion sequence}

In order to obtain a clear differentiation between nonneoplastic and neoplastic tissue, at least a high diffusion $b$ value is required, which in the PI-RADS v2 was established as a minimum of 1,400. A retrospective study carried out in 2016 by Rosenkrantz and others showed that $b$ values between 1,500 and 2,500 are optimal for cancer detection, since with these values it is possible to differentiate inflammatory or fibrotic lesions, which are "extinguished with high b values", from neoplastic ones.

Since very high $b$ values are required, the problem of the low signal-to-noise ratio (SNR) in these sequences arises, and it is for this reason that in order to perform a good MRI-mp of the prostate, equipment with a magnetic induction of 3 Tesla or 1.5 Tesla is required, ideally with an endorectal coil, which improves the signal-to-noise ratio (SNR). In the latest version of PI-RADS 2.1 it is recommended to make acquisitions with a low b set $(0$ - $100 \mathrm{sec} / \mathrm{m} \mathrm{m}^{2}$ ) and an intermediate one (800-1000 sec/ $\mathrm{mm}^{2}$ ), with which the ADC Map is calculated. In addition, a high b must be acquired or calculated, (greater than $1400 \mathrm{sec} / \mathrm{mm}^{2}$ ), this value is excluded from the ADC map calculation in order to avoid the Kurtosis effect.

\section{PET / CT}

In recent years, technological advances in some modalities have made it possible to improve the efficacy and efficiency of the diagnosis and treatment of prostate cancer. Multi-Parametric Magnetic Resonance (mpMRI) has been a huge advance in this regard, also fused image-guided biopsy techniques, etc. But there has also been a great evolution in the field of Nuclear Medicine, mainly in the use of PET / CT. In this post we will talk about the advantages of PET / CT with two different radiopharmaceuticals in the study of this pathology. A classic bone scan in a patient with prostate cancer and bone metastases, this low-cost test continues to be extremely useful.

18F-choline PET / CT: This radiopharmaceutical has demonstrated superiority in the detection of pathological lymph nodes and distant metastases compared to other diagnostic modalities. Diseased tissues show an increase in the uptake or accumulation of this radiopharmaceutical. 18F-choline is far superior to the most widely used PET radiopharmaceutical, 18F-FDG, in detecting this type of cancer. This test is usually requested in patients already treated for prostate cancer, with elevated levels of the PSA marker in the blood and with other negative imaging tests such as bone scan or CT.

PET / CT with 68Ga-PSMA: PSMA is a membrane-specific prostate antigen, it is present in normal prostate tissue, but increases its concentration in diseased tissue, it is a promising biomarker not only used in diagnosis but also with potential therapeutic. By being able to mark with 68Ga, it becomes a very effective detector of areas in which there are local recurrences or relapses, affected lymph nodes and distant metastases.

Although it is too early to say so, some studies suggest an advantage of this tracer over 18F-choline, especially at lower PSA levels (see bibliography). What is clear is that some images that are not visible in other modalities are detected thanks to this new radiopharmaceutical. This advantage is still being investigated and evaluated. From the technical point of view of the administration of the radiopharmaceutical and the acquisition of the images, both mentioned options are relatively simple to implement. In the case of $18 \mathrm{~F}$-choline, a localized acquisition is made in the pelvis a few minutes after injecting the radiopharmaceutical (5 minutes is suggested) and another in the whole body after one hour after the injection. Some hospitals use iodinated contrast in CT acquisition, while others do not. For the PET / CT study with 68Ga-PSMA, some authors indicate a single acquisition of the whole body at the time of administration of the radiopharmaceutical.

Both options mentioned in this article are expensive to produce and are not yet available in many places. We hope that the effort in the research and development of these new molecules will have an impact on the improvement of the staging and post-treatment assessment of this disease. While the pertinent verifications are made and their use is generalized, the professionals involved must prepare us to be up to date with these advances by informing ourselves and understanding the potential of these techniques. These iconographic studies are always accompanied by a PSA test and a complete laboratory routine.

For the patient with advanced disease, in whom the response to the hormonal and non-hormonal treatments instituted is being 


\section{Cancer Therapy \& Oncology International Journal}

evaluated, the total body bone scan is very important, to visualize if the pathological hyper uptake points decrease with the treatment, if the serum levels of PSA decreased or normalized and localized radiographs for evaluation of osteoblastic metastases and their evolution during these treatments. It is evident that in advanced patients, performance status is also an important parameter of evolution and response to treatment, but with limited (subjective) value.

\section{Localized Treatment of Prostate Cancer}

When prostate cancer is confined to the gland, both surgery and radiation therapy are used with success.

However, the important thing in this group of patients also, for either of both procedures is to reduce morbidity. In the absence of randomized studies that demonstrate a superiority of surgery over radiotherapy, decisions are largely made by patients after medical consultation.

\section{Radical Prostatectomy}

Radical prostatectomy has several advantages: examination of the specimen allows a definitive knowledge of the pathological stage and degree of the disease. Patients can be stratified according to the pathological stage of their disease. If the Gleason score is 2 to 4 and the clinical stage is T1c (e.g., the patient has an elevated PSA without a palpable mass), the survival-free progression rate after radical prostatectomy is approximately $90 \%$; if the Gleason score is 5 to 6 , the rate is approximately $80 \%$; if the score is 7 , the rate is approximately $55 \%$, and if the score is 8 to 10 , the rate is less than $20 \%$.

For patients stratified as T2, the probability of disease-free progression at 15 years is approximately $69 \%$.

The higher the Gleason score, the more extensive the disease, the greater intraoperative and postoperative complications occur. Intraoperative procedures include bleeding and injury to the obturator nerve, urethra, rectum, or a major pelvic artery or vein. Postoperative complications alter the quality of life of the patient, and are: incontinence, impotence, and ureterovesical stricture. The incidence of the latter varies between 1 to $9 \%$. The incidence of incontinence is approximately $8 \%$, with $6 \%$ of patients presenting with stress incontinence and $2 \%$ of patients using more than one diaper per day. Regarding sexual impotence, only $31 \%$ of patients report having an erection and $9 \%$ a satisfactory sexual act.

\section{Radiotherapy}

The advantages of external radiation therapy as the primary treatment for localized disease is that it presents the patient with a low risk of urinary incontinence and stricture. Radiation therapy can eradicate tumor extensions around the prostatic capsule, and when combined with hormone therapy, it offers a chance of cure for some patients, such as those with intermediate-risk tumors. The disadvantages of radiation therapy are that the treatment is long, eight to nine weeks; A special three-dimensional technique is required that allows the administration of doses of at least 72 Gy, which are those required for correct treatment (Figure 10 \& 11).

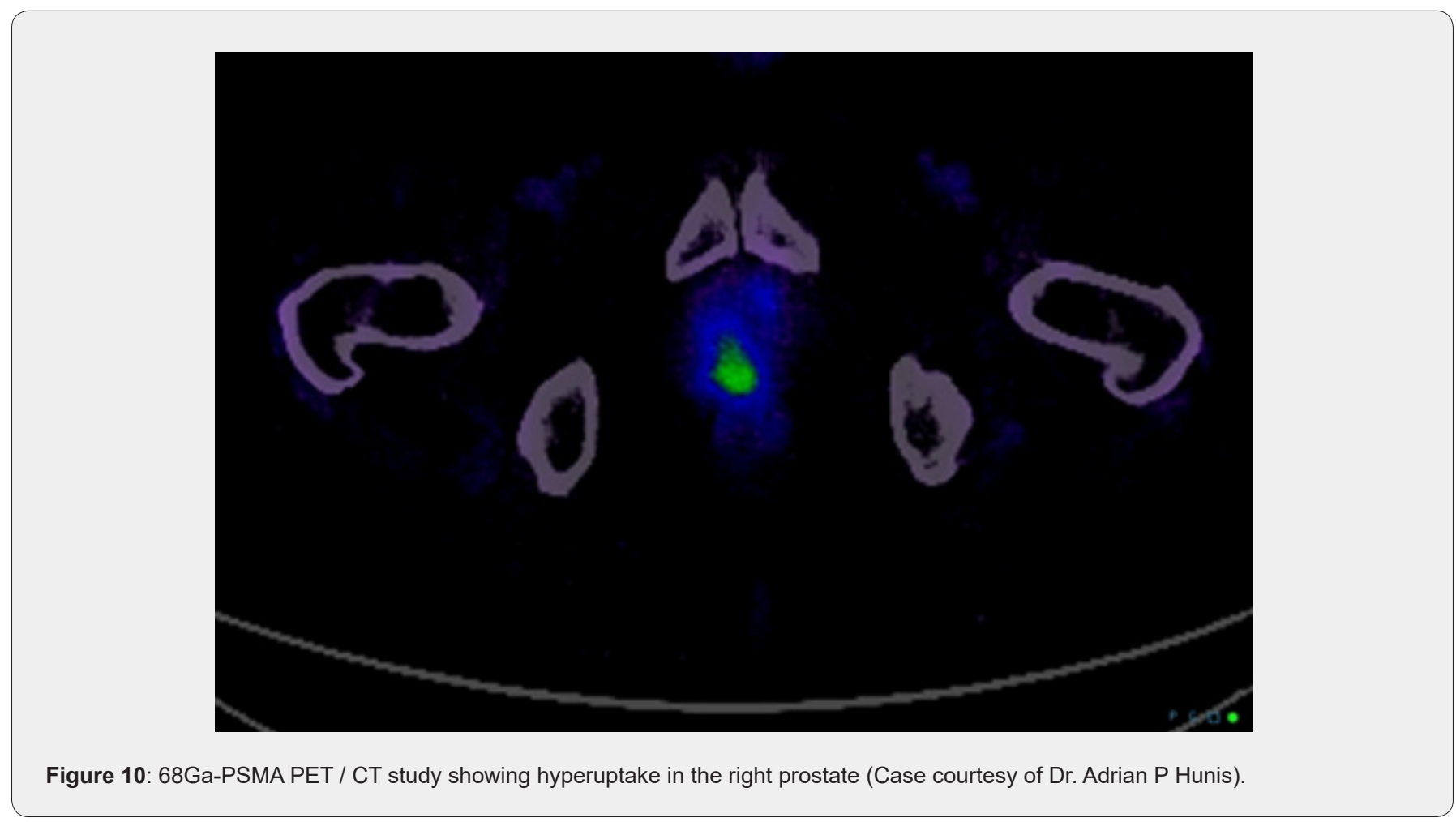




\section{Cancer Therapy \& Oncology International Journal}

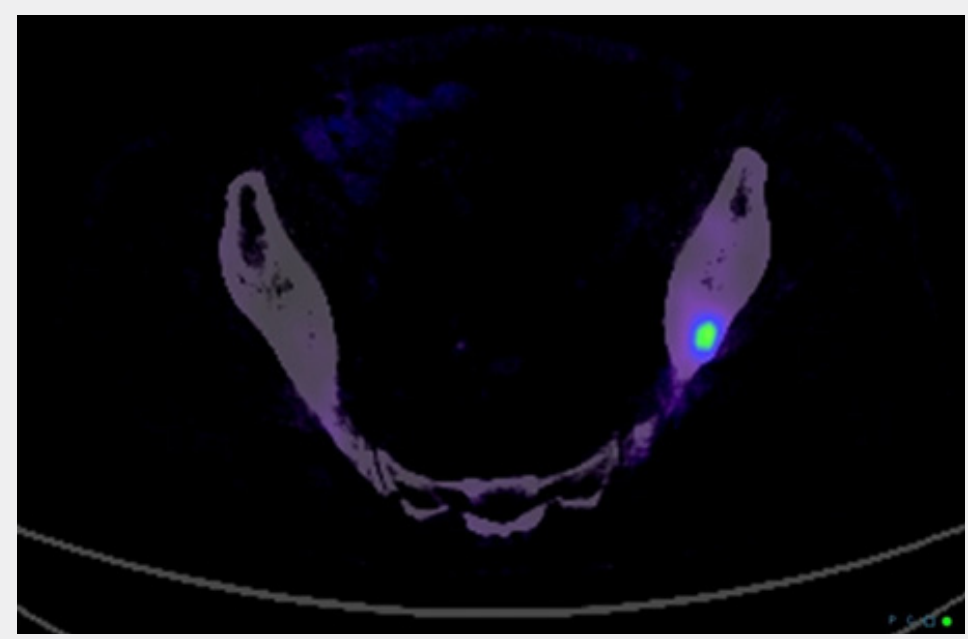

Figure 11: Small bone metastasis not visible by TC (Case courtesy of Dr. Adrian P Hunis).

Also, this treatment does not inform the oncologist about possible metastases in the lymph nodes, and the long-term sequelae of high-dose radiotherapy are not known. The Po the possibility of relapse-free survival after radiotherapy, with the use of post-treatment PSA levels as a monitoring criterion, can be predicted by the risk-group of patients at the time of presentation. For patients with low-risk tumors (stage T1c, Gleason score of 6 or less, and a PSA level of $10 \mathrm{ng} / \mathrm{ml}$ or less), the rate is 70 to $80 \%$. For patients with intermediate-risk tumors (stage T2, Gleason score of 7, PSA between 10 and $20 \mathrm{ng} / \mathrm{ml}$ ) the rate is $50-55 \%$. In the last decade, the development of conformational and three-dimensional therapy, which uses computer software to integrate computed tomography images of the internal anatomy of the patient in the treatment position, has allowed the volume of tissue to be a high dose of radiation therapy is administered to more closely conform to the shape of the tumor. This advancement has reduced the incidence of both early and late toxicities in normal tissues and allows higher cumulative doses to be administered with a reduced risk of late effects. There is now evidence from randomized and non-randomized studies that a significant improvement in disease-free relapse rates in patients with intermediate-risk tumors when doses greater than 70 Gy are used (Figure 12).

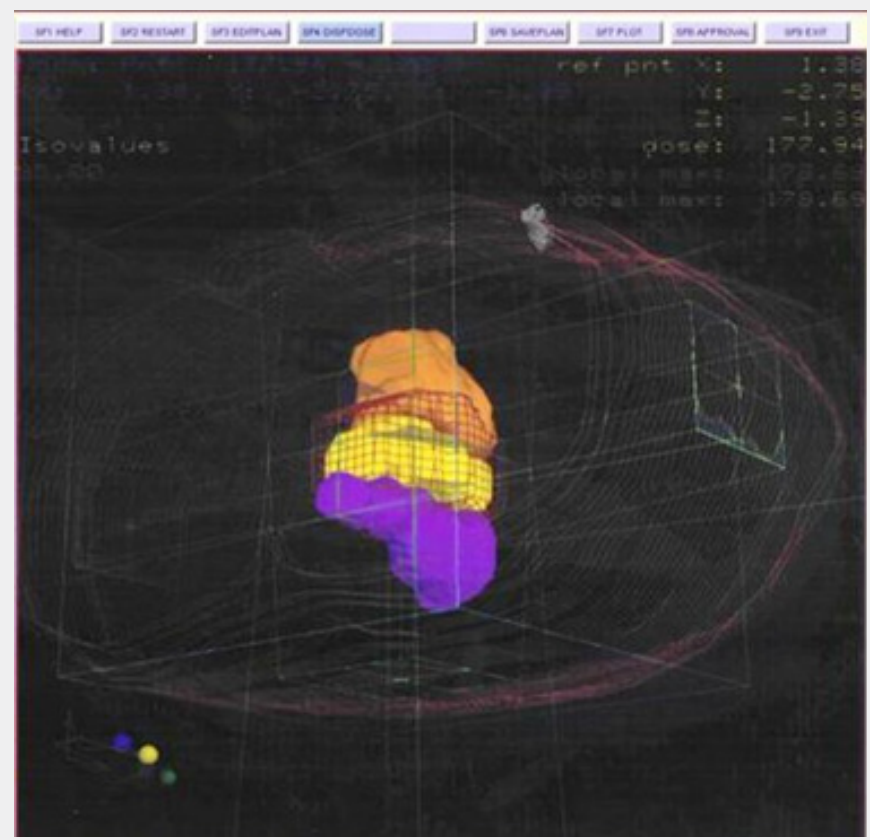

Figure 12: (Case courtesy of Dr. Adrian P Hunis). 


\section{Cancer Therapy \& Oncology International Journal}

Strict contraindications to external radiation therapy include: previous pelvic irradiation, active inflammatory bowel disease, indwelling Foley catheter, severe obesity. The other type of radiation therapy is brachytherapy or interstitial radiation therapy, whereby iodine 125 or palladium 103 seeds are implanted directly into the tumor. This last modality presents a favorable toxicity profile and promising control rates at 5 and 10 years of follow-up. The downside is that not all centers are trained in this modality.

\section{IMRT}

Intensity modulated radiation therapy is an advanced form of 3D-CRT. It constitutes one of the most important technical advances in recent years, representing a radical change in the planning and administration of treatment. Like 3D-CRT, IMRT requires 3D planning with delimitation in axial sections of the volumes of interest. However, in IMRT, in addition to defining the goal of total doses needed in the tumor volume, the doctor establishes the dose restrictions necessary to protect the different normal tissues involved. According to these indications, the computer elaborates, based on a calculation algorithm by trial and error, an irradiation plan that satisfies the required dose profiles. This optimization process is known as reverse planning.

Intensity-modulated radiation therapy, such as 3D-CRT, uses multiple beams of shaped radiation that converge on the tumor target from various entry angles. But unlike it, each treatment field is formed by the sum of several segments, so that different levels of dose intensity are generated at the different points of each field (Figure 1). This effect is achieved with a multilayer collimator, a device designed to shape the radiation beam using multiple motorized blocks. The doses delivered by the sum of the fields creates in the patient a treatment volume in which the normal organs and tissues are located in restricted areas and the tumor tissue in the areas of greater exposure (Figure 2).

The use of intensity-modulated radiation therapy has become popular over the last 15 years and has been rapidly adopted in multiple centers around the world mainly because of its dosimetric characteristics, despite a sometimes-incomplete understanding of its benefits, limitations, and radiobiological implications. and of the incipient evidence of its potential final clinical benefits. IMRT has several obvious dosimetric advantages over conventional 2D and 3D conformal radiation therapy. It allows to significantly reduce the amount of normal tissues subjected to high doses of radiation, with the potential reduction of the risk of acute and chronic complications. It is capable of producing much more homogeneous dose distributions and conformed to the anatomy of the volumes involved, (Figure 3) reducing the shadow areas at the limits of the target volume. These factors allow dose escalation in tumor tissue and a simultaneous reduction in dose in normal organs, with the consequent increase in the therapeutic range. Finally, the treatment plan can be designed considering different dose / fraction for different volumes, allowing to achieve different radiobiological conditions for normal and tumor tissues that can improve even more the response. Tumor side and functional preservation.

The high degree of precision that can be achieved with the use of intensity-modulated radiation therapy is the result of a chain of optimized procedures that begins with the localization of the tumor in the patient's body through diagnostic imaging studies, CT, MRI, PET among others, and is completed with the delivery of a radiation dose in a course of 30 to 40 therapy fractions. Among them are the correct delimitation of the target volumes and the organs at risk, the simulation of the therapy, the calculation of the doses, the optimization process, inverse or not inverse, the correct positioning of the patient on the therapy table and verification with images prior to each treatment fraction. Each of these links must be made under strict quality control to rule out any possibility of error. It is necessary to consider that tumors are not static, being able to present mobility, reduction in size due to response to treatment, deformations and eventually increase in volume throughout therapy. Patients may also present changes, due to edema, variations in body weight, movements of the viscera or differences in the volume of their contents, in addition to the movements produced by breathing. These changes determine the risk that the normal tissues that make up the restriction volumes may remain positioned in high dose areas during irradiation and that the tumor target may leave it, determining an increase in complications and a greater possibility of failure in control. tumor. These multiple uncertainties, which constitute the main limitations of IMRT, have led to the development of additional quality control methods to ensure its correct performance. These include image-guided radiation therapy (IGRT), respiratory monitoring, and 4-D radiation therapy. Other limitations of IMRT that should be considered are the possible inclusion of large volumes of healthy tissues in areas exposed to low doses of radiation, determined by the use of multiple treatment fields and the greater total body exposure due to an increase in the duration of each treatment. fraction. The consequences of these, which could be especially important in pediatric patients undergoing IMRT, have not been established so far.

In recent years, numerous studies have been published that prove the dosimetric advantages of IMRT. The key question, however, is what are the clinically relevant advantages that IMRT has over other conventional techniques? This has been partially answered by direct and indirect clinical studies that have determined the existing correlation between the doses received by each organ and its subsequent function, producing valuable information on the dose-volume relationships and toxicity for different tissues, which is currently used in IMRT planning.

There is still no definitive evidence of the clinical advantage of IMRT in prostate cancer. It is difficult to establish a reliable comparison between the published studies since they have 
differences in radiation techniques, fractionation, definition of target volume, safety margins, dose restrictions and organs at risk. In some, the entire pelvis is considered white volume. In others, only the prostate with or without the seminal vesicles. Historical controls are used in most comparative studies, which is especially inappropriate when considering the progress made by diagnostic procedures and the greater standardization of histology that have produced a migration of state, or Will Rogers phenomenon. Finally, adoption of image-guided radiotherapy for patient positioning and more careful observation of dose-volume-toxicity and doseresponse relationships may have contributed to the reduction of toxic effects in IMRT studies. There is, however, some consensus that IMRT, alone or as part of optimized radiotherapy techniques, allows dose escalation, reducing the incidence of gastrointestinal and genitourinary toxicities and the impact on sexual function. For this reason, IMRT has been included in the NCCN clinical practice guidelines as a standard of treatment, considering the use of IGRT if dose escalation is indicated.

\section{Treatment by Stage / Oriented Prostate Cancer}

\section{Stage T1}

In stage $\mathrm{T} 1 \mathrm{a}$, control is performed every 6 months with digital rectal examination and PSA. In stages T1b and T1c according to the estimated life expectancy of the patient, if it is considered that this will be less than 10 years due to comorbidity, the possibility of controlling it without treatment will be discussed. If the patient accepts the control and is asymptomatic, he will remain under observation. If the patient did not accept to control or have symptoms as a result of your prostate disease, you will then receive treatment. If the patient is under 80 years of age, radiation therapy will be indicated, either external (preferably three-dimensional shaped: 3D) or interstitial (brachytherapy). Optionally, the urologist can perform radical prostatectomy.

If the patient is older than 80 years, hormone therapy will be indicated, and optionally either external radiation therapy or brachytherapy. If it is considered that life expectancy is greater than 10 years, radical prostatectomy or radiotherapy will be performed, be it external or brachytherapy.

\section{Stage T2}

If the patient presents a Stage T2a with a life expectancy greater than 10 years, the procedure will be that of radical prostatectomy or external radiation therapy (3D) or brachytherapy. In any T2 (T2 $a, b, c)$, if a life expectancy of less than 10 years is considered due to comorbidity: it is discussed with the patient to control it without treatment. If the patient accepts the control and is asymptomatic, it is under observation. If the patient does not accept control or has symptoms, they will receive treatment. If the patient is under 80 years of age, external radiotherapy or brachytherapy will be indicated at any $\mathrm{T} 2(\mathrm{a}, \mathrm{b}, \mathrm{c})$.
In $\mathrm{T} 2 \mathrm{~b}$ and $\mathrm{T} 2 \mathrm{C}$ with or without prior adjuvant hormone therapy for 3 to 6 months. Optionally, the urologist can perform radical prostatectomy. If the patient is older than 80 years, hormonal therapy will be indicated, optionally radiotherapy in Stages $\mathrm{T} 2 \mathrm{~b}$ and $\mathrm{T} 2 \mathrm{c}$. If the estimated life expectancy is greater than 10 years, radical prostatectomy or radiation therapy, either external (3D) or brachytherapy, with or without prior neoadjuvant hormone therapy for 3 to 6 months, will be indicated.

\section{Stage T3}

Hormone therapy is indicated in all cases. If the patient is under 80 years of age: neoadjuvant hormone therapy is indicated for 3 to 12 months at the discretion of the specialist. After that period, the patient is reevaluated. If there is a good local response and the estimated life expectancy is greater than 10 years, radical prostatectomy or three-dimensional conformal (3D) external radiation therapy or brachytherapy is indicated. If life expectancy due to comorbidity is less than 10 years, hormonal therapy can be continued definitively or preferably conformal external radiation therapy (3D) or brachytherapy preferably complementary to external radiation therapy may be indicated. Optionally after prostatectomy or radiotherapy, adjuvant hormone therapy can be performed for 3 to 6 months.

If, upon reevaluation of the patient after neoadjuvant therapy, the local response is insufficient to consider curative treatment, definitive hormone therapy is indicated. Optionally or if there is local symptomatic progression, palliative prostate radiotherapy (preferably 3D) may be indicated. If the patient is older than 80 years, remains in definitive hormonal therapy or if during definitive hormonal therapy the patient presents symptomatic local progression, prostate palliative radiotherapy (preferably 3D) may be indicated.

\section{Advanced Disease. Hormonal Treatment}

Definitive hormonal treatment is indicated in any $\mathrm{T}$ with the following conditions:

Patients with comorbidities that contraindicate surgery or radiotherapy. Patients with PSA greater than $50 \mathrm{ng} / \mathrm{ml}$. If there is humoral progression after: Radiation therapy when the PSA is greater than 7. Prostatectomy when the PSA is greater than 4. In Stages T1b-T1c- T2 in patients older than 80 years with less than 10 years of life expectancy, who do not accept control or have symptoms as a consequence of their prostate disease. In T3 after reassessing the local response to neoadjuvant treatment or in those over 80 years of age. Stage T4 or Stage N1-2-3 or M1.

Prostate Cancer, Advanced or Recurring Disease Systemic Treatment

Prostate cancer constitutes the paradigm of the tumor in which the dependence of hormonal stimulation (androgens) on 


\section{Cancer Therapy \& Oncology International Journal}

tumor progression was identified decades ago. Hence, androgen deprivation has been the focus of treatment for metastatic disease, as well as for certain non-disseminated disease conditions (e.g. neoadjuvant).

Two clinical situations are identified in relation to hormone therapy, which we will consider in order to evaluate the therapeutic options.

The patient:

a) Sensitive to castration

b) Castration resistant

Castration Sensitive Disease Lhrh Analogues + Antiandrogens or Lhrh Antagonists

The use of the so-called "complete androgen blockade", the association of LHRH analogues + antiandrogens, is common. More appropriately, it should be called "dual androgen blockade" since it does not know the adrenal pathway for androgen synthesis, thus not being a "complete block". A meta-analysis that has evaluated patients treated with the combination of analogs + antiandrogens vs analogues in monotherapy, has not shown differences between the two treatments at 24 months. At 60 months, a modest increase in survival has been observed in the group treated with the combined blockade. For this reason, depending on the impact on survival and toxicity secondary to the combination, the suggestion would be that the treatment be only combined in the first month, to avoid the flare secondary to the initial increase in androgens by the analogues, and then suspend them , continuing only with the analog. For situations that require a rapid antiandrogenic effect, e.g. spinal compression, surgical castration is the preferred procedure, a procedure that achieves castration plasma testosterone levels in the shortest possible time.

Optionally, the analog (agonist) can be replaced by a pure antagonist of the releasing factors, which has the peculiarity of inducing castration plasma testosterone levels within 48 to 72 hours. As it does not produce flare, it does not need to be associated with an antiandrogen. Faced with the progression to initial hormonal treatment, subsequent hormonal manipulations are usually carried out depending on the previous therapeutic decision, e.g. If only LHRH analog, added antiandrogen

If dual block, try Antiandrogen Suppression (SAA) Consider estrogen therapy in patients without cardiovascular risk. Eventually consider Ketoconazole. In practice, numerous hormonal manipulations are carried out, some with a certain logic, others lacking it, which lead to the deterioration of the patient and the impossibility of exposure to other treatments due to impaired Performance Status (PS). Many times, these manipulations delay the diagnosis that the patient has evolved to a disease resistant to castration maneuvers.
Incorporation of Chemotherapy Early, Associated with Hormone Therapy in Castration-Sensitive Disease

Three studies have been published that include early chemotherapy with DOCETAXEL associated with HORMONE THERAPY.The first of them was GETUF GA 15 in metastatic patients, although negative, since it did not meet its Primary Objective (OP) of Overall Survival (OS): at 82.9 months of follow-up it showed OS: 60.9 vs 46.5 months (HR $=0.90 \mathrm{P}=0.44)$. However, it did modify the Secondary Objectives (OS): Progression Free Survival (PFS) both Clinical (23.5 vs 15.4 months), and by PSA (22.9 vs 12.9 months) showed benefit for the arm of the combination of deprivation therapy. androgens (ADT) with Docetaxel.

The second study, CHAARTED, also carried out in metastatic patients, showed a clear benefit in OS in favor of the arm of the combination with Docetaxel (57.6 vs 44 months), identifying a greater benefit in the group of patients with high volume of disease. High volume is defined in this study as visceral disease and / or 4 or more bone lesions, with at least one of them in an extra axial location. A 17-month benefit was observed in OS, the results for the low-volume group having not yet been achieved.

The third and last clinical trial confirming the incorporation of Docetaxel in this group of patients is STAMPEDE. In 61\% they were M1 and 39\% M0 unlike the previous ones, which included only M1 patients. It showed a $24 \%$ decrease in the risk of death, with a difference in OS of 77 vs 67 months in favor of the combined arm. There was also a $38 \%$ decrease in the risk of relapse, evidenced by a difference of 37 vs. 21 months in PFS. The Mean Survival (SM) was 60 vs. 45 months in favor of the combination of Docetaxel plus HT with a 5 -year survival of 50 vs. $39 \%$.

In an analysis by Dr. Claire Vale's group of all these studies s clearly an improvement in OS was demonstrated in metastatic patients, with a benefit of $10 \%$ (an increase from 40 to 50\%) at 4 years with a prolongation of PFS of $15 \%$ (from 80 to $65 \%$ ) at 4 years on the other hand, in the group of patients M0 the benefit in OS it was only $5 \%$ (from 80 to $85 \%$ ) at 4 years, as well as a prolongation in PFS of $8 \%$ (70 to $62 \%$ ). Given these results, in castration-sensitive metastatic patients with visceral disease and high-volume bone involvement, as defined above, adding Docetaxel to HT treatment at the start of treatment should be considered as STANDARD. At the moment, the use of Docetaxel plus ADT in the group of non-metastatic patients cannot be endorsed, requiring greater evidence of benefit as well as longerterm follow-up.

\section{Castration Resistant Prostate Cancer (CRPC)}

\section{Definitions}

We consider two definitions in this situation, that of the Prostate Cancer Working Group 2 (PCWG2) and that of the 
European Association of Urology, (USA)

A.1 PCWG2, biochemical failure (PSA only), in a patient with serum testosterone levels compatible with castration, namely: a. Increase $>2 \mathrm{ng} / \mathrm{ml}$, above nadir

b. at least $25 \%$ above it

c. confirmed by a second determination after 3 weeks

A.2 USA, defines this condition as the one that occurs in a patient with:

to. Serum testosterone levels $<50 \mathrm{ng} / \mathrm{dl}$ or $<1 / 7 \mathrm{nmol} / \mathrm{l}$

b. Presenting 3 consecutive elevations of PSA separated by 1 week, resulting in 2 elevations $\geq 50 \%$ above nadir, with PSA $>2$ $\mathrm{ng} / \mathrm{ml}$

c. The SAA must have been tried which will be 4 weeks for Flutamide and 6 weeks for Bicalutamide

d. PSA progression despite consecutive standard hormonal manipulations Camera

and. Appearance of at least 2 new lesions in Bone Gamma

or in soft tissues, measured by RECIST1 $(\geq 2 \mathrm{~cm})$.

To synthesize then, once the biochemical and / or clinical progression has been verified as defined above, one must:

Confirm the castration status: determination of plasma testosterone

Confirmed the same, the Suppression of Antiandrogen should be tested

1 Response Evaluation Criteria in Solid Tumors.

\section{Different situations should be considered when diagnosing CRPC:}

a) Exclusive biochemical failure

b) Evidence of metastatic disease (M1)

c) Clinical condition of patient M1, asymptomatic, minimally symptomatic or symptomatic

d) Performance Status (PS)

Previous treatment to which the patient was subjected (Chemotherapy yes vs no)

Associating these different variables, we have the following clinical situations:

a) Asymptomatic or minimally symptomatic patient, without prior chemotherapy b) Symptomatic patient, with good PS, without previous chemotherapy

c) Symptomatic patient with bad PS, without previous chemotherapy d. Symptomatic patient, with good PS and previous Docetaxel and symptomatic patient, with bad PS and previous Docetaxel.

These different situations will be conditioning factors of the proposals to the patient. They could range between specific therapeutic interventions and palliative care. First line of treatment (note that chemotherapy or hormone therapy but lines of treatment). Before discussing the different treatment options available for CRPC patients, it should be clarified that all these new drugs have been tested in patients with evidence of metastatic disease, generally asymptomatic or minimally symptomatic, and with PS 0-2.

These do not constitute minor data when defining the particular treatment for each patient, since they delimit the population in which the therapeutic benefit is demonstrated. Likewise, it should be clear that those patients with CRPC with exclusive biochemical failure are therefore not candidates for these therapeutic manipulations. In these particular cases, it is recommended to continue hypothalamic pituitary inhibition by LH RH analogs or antagonists, but not to introduce any of these medications in the absence of documentation of metastatic disease.

\section{Docetaxel + Prednisone}

It was the first chemotherapy association that had an impact on progression-free survival (PFS). That patient with dominant visceral disease, symptomatic and with good PS, constitutes the ideal patient, since chemotherapy offers the responding patient a possibility of rapid response. As is widely known, in recent years the results of studies in this patient population have been published, which have significantly expanded the therapeutic armamentarium. These options are discussed below.

\section{Abiraterone $1000 \mathrm{mg}$ + prednisone + LHRH analog}

Abiraterone is an inhibitor of adrenal steroid production, acting at the level of the CYP17 complex, which not only affects androgen synthesis, but also that of mineralocorticoids and glucocorticoids, which requires a knowledge of the functioning of this hormonal axis in order to maintain its balance and prevent toxicities.

This drug has shown utility both in patients who fail Docetaxel and in those who have not received it, and it has approval from the regulatory authorities in both scenarios (M1 patients, pre and post Docetaxel). The COUA 301 and 302 studies have shown this, presenting prolongation of progression-free survival (PFS) when compared with placebo, the impact on OS is affected given the high rate of Cross Over. 


\section{Cancer Therapy \& Oncology International Journal}

The addition of Prednisone reduces the incidence of them. The decision must be made based on: Comorbidities that limit the use of one or another medication Condition of the disease, the patient with a great burden of disease, particularly visceral, possibly from maintaining an adequate PS benefits more from chemotherapy.

\section{Enzalutamide}

Enzalutamide, a potent antiandrogen with a high affinity for the Receptor Androgenic, it has shown efficacy in the pre and post Docetaxel scenarios. The results of the PREVAIL trial have recently been published, in which the drug has been studied in chemotherapy-naïve patients. In them, it has been shown to be highly effective, prolonging the parameters under study significantly. The risk of seizures should be considered, which, although it has been significantly reduced with the recommended dose of $160 \mathrm{mg}$, could be increased in patients with a history of epilepsy or cerebrovascular accident (CVA).

C. Castration resistant patient progressing to first line of treatment, depending on the first line, the options would be: Docetaxel + Prednisone, or Abiraterone or Enzalutamide or Cabazitaxel The AFFIRM study demonstrated the impact of Enzalutamide on PFS when compared to placebo and formed the basis for the registration of the drug, leading to an early closure in the interim analysis. Cabazitaxel is a taxane that has proven useful in patients progressed to Docetaxel (TROPIC trial). The patient's situation, age, and comorbidities should be considered for this indication, given his hematological toxicity that has required the addition of granulocyte-macrophage colony-stimulating factors. It is an option for those who are able to receive it.

As can be seen, in the decision regarding a patient who has progressed to the first line in the situation of CRPC, several factors must be taken into account. It is a decision in which both chemotherapy and hormonal therapy options should be considered, with clinical judgment and the notion of a possible therapeutic sequencing being important. The best therapeutic sequence is not clearly defined at the moment. However, it would appear that direct Abiraterone sequencing followed by Enzalutamide or vice versa would not offer major advantages. Therefore, the option of chemotherapy with Docetaxel after the failure of one of these molecules in CRPC would perhaps be appropriate.

\section{Bone Antiresorptive Treatment}

Prostate cancer is associated with high frequency with the occurrence of bone metastases, which exposes these patients to the risk of secondary complications, pain, fractures, spinal compression. Also, the age of the patients and the antiadrogenic treatments increase the risk of osteopenia and osteoporosis. Bone mineral density is not studied as rigorously in males as in females, however, in the face of these risks it must be considered. Bone antiresorptive treatment has modified the natural history of those patients with bone metastases from various tumors, and it must be borne in mind as a treatment associated with the specific antitumor.

\section{Bisphosphonates}

Zoledronic Acid has been shown to induce a prolongation of the appearance of related bone events, such as a decrease in the incidence of fractures and spinal cord compression, in prostate cancer in particular.

We currently have Denosumab, an anti RANKL2 antibody, which has the advantage of being able to be used in patients with impaired renal function, which is usually limiting in the case of zoledronic acid and can be administered subcutaneously. 2 Receptor Activator for Nuclear Factor $\kappa$ B Ligand. In both cases, calcium, kidney function, and vitamin D levels should be monitored, and the risk of osteonecrosis of the jaw should be monitored, which has been reported with both drugs.

\section{Radioisotopes}

Radioisotopes have also been used in these situations. Strontium and Samarium, although they have been associated with transient subjective improvements, have been myelotoxic and this has limited their use.

Radium 223, (Alpharadim), is an alpha particle emitting isotope, which produces a break at the level of the DNA double helix with minimal to exposure of surrounding tissues. This makes the myelotoxicity profile significantly different from previously known isotopes. In a phase III trial (ALSYMPCA), in symptomatic patients with or without prior chemotherapy, not only a prolongation of the appearance of bone-related events and an improvement in quality of life has been observed, but also a prolongation of the mean survival of the patients treated as opposed to those receiving placebo.

This suggests not only an effect on bone metabolism but also a specific effect on disease. Radium 223 is particularly indicated in patients with castration-resistant prostate cancer, symptomatic with exclusive bone disease, both in those who maintain a good PS, as well as in those with deterioration of the same attributable to the disease.

\section{Palliative Care}

Although specific treatment constitutes the core of the treatment of patients with advanced prostate cancer, we must always bear in mind that palliative care must run in parallel with specific treatment. The palliation of the symptoms of our patients is fundamental, resulting in an improvement in their quality of life, and in the face of a deterioration of the PS and the decision to discontinue specific treatment, palliative care emerges as central, in patients suffering from a disease that Despite their advanced state they can survive for a long time, and this time must be of the best possible quality. 


\section{Current controversies about hormone therapy}

Not all studies agree on the many issues related to hormone therapy, such as the best time to start or stop therapy and the best way to give it. Studies are underway that are looking at these issues. Some of these issues are discussed below.

\section{Early Stage Cancer Treatment}

There is research proposing hormone therapy rather than observation or active surveillance in men with early-stage prostate cancer who do not want to have surgery or radiation. Studies have not found that these ho Others live longer than those who only receive treatment when the cancer progresses or when symptoms develop. Because of this, hormone treatment is generally not recommended for early-stage prostate cancer.

\section{Early treatment or late treatment}

For men who need (or will need in the future) hormone therapy, such as men whose PSA levels are increased after surgery or radiation, or men with advanced prostate cancer who do not yet have symptoms, not always it is known when to start hormonal treatment. Some studies suggest that hormone therapy works best if it is started as soon as possible, even if the man feels fine and has no symptoms. Some studies have shown that hormone treatment can slow down the disease and perhaps even help men live longer.

However, not everyone agrees with this method. More evidence is expected to show that there are benefits. They believe that treatment should not be started until a man has symptoms of cancer, due to the side effects of hormone therapy and the possibility that the cancer will sooner become resistant to therapy. This issue is still under study.

\section{Intermittent hormone therapy versus continuous therapy}

Most prostate cancers treated with hormone therapy over a period of months or years become resistant to this treatment. Some studies suggest that constant androgen suppression may not be necessary, so they recommend intermittent treatment. The intention is that the interruption of androgen suppression will also provide men with a break from side effects such as decreased energy, sexual problems, and hot flashes.

In a type of intermittent hormone therapy, treatment is stopped when the PSA in the blood drops to a very low level. If the PSA level begins to rise, the drugs are started again. Another method of intermittent therapy uses hormone therapy for fixed periods of time, for example it is given for 6 months and is off for the next 6 months.

At this time, it is not known what benefits this approach has over continuous hormone therapy. Some studies have found that continuous therapy can help men live longer, but other studies have found no such difference.

\section{Combined androgen blockade}

There are studies that treat patients with androgen deprivation (orchiectomy or LHRH agonist or antagonist) and an antiandrogen. Some studies have suggested that this may be more helpful than androgen deprivation alone, although other studies do not agree with this. There is not enough evidence to indicate that this combination therapy is better than starting with a single drug to treat prostate cancer that has spread to other parts of the body.

\section{Triple androgen blockade}

Studies have suggested adding an additional step to combination therapy by adding a drug called a 5-alpha reductase inhibitor, either finasteride (Proscar) or dutasteride (Avodart), to the combined androgen blockade. At present, there is very little evidence to support the use of this triple androgen blockade.

\section{Castration-sensitive, castration-resistant, and hormone-refractory prostate cancer}

These terms are sometimes used to describe how well a patient's cancer responds to hormone therapy.

a) Castration-sensitive prostate cancer means that the cancer is being controlled by keeping testosterone levels as low as they would be expected if the testicles had been removed (referred to as the castration level). Levels can be maintained at this low amount by an orchiectomy or by administering either an LHRH agonist or antagonist.

b) Castration-resistant prostate cancer means that the cancer continues to grow even when testosterone levels are as low as would be expected to be at or below the castration level. Some of these cancers may benefit from other forms of hormone therapy, such as abiraterone or some of the newer antiandrogens.

c) Hormone-refractory prostate cancer refers to prostate cancer that no longer benefits from any type of hormone therapy, including newer medications.

\section{Hormono Refractory Prostate Cancer (CPHR)}

\section{Background}

About $30 \%$ of patients with prostate cancer present as " $D$ " stages of disease, that is, with metastases at the time of diagnosis, while $20-25 \%$ of patients develop distant metastases during tumor evolution. The standard of care for disseminated prostate cancer is androgen suppression hormone therapy. The treatment obtains a high percentage of remissions (between $70-80 \%)$, although in a period of 12 to 18 months the tumor evolves towards a hormone-resistant phase with a survival that does not usually exceed 6-12 months. In this situation, secondline hormonal treatments with estrogens, aminoglutethimide, ketoconazole, progestogens, corticosteroids or antiandrogens obtain a response rate of less than $20 \%$ with a duration of 4-6 


\section{Cancer Therapy \& Oncology International Journal}

months. Traditionally, prostate cancer has been considered a chemo resistant tumor. In the 1980 s, various cytostatics showed low activity in patients with HRPC, with an objective response rate of less than $10 \%$ and a mean survival between 6 and 12 months, similar to that obtained with supportive treatments. However, in recent years the treatment of hormone-resistant prostate cancer has undergone profound changes.

The systematic determination of PSA levels has allowed the diagnosis of HRPC in earlier stages, in patients with a better performance status, which can facilitate the efficacy and tolerance of chemotherapy treatment. Likewise, given the absence of measurable tumor lesions in the majority of patients with HRPC, the decrease in PSA levels has been used as a marker of chemotherapy efficacy, despite the fact that various evidences indicate that variations in levels PSA levels do not always correlate with the course of the disease.

Various cytostatic have shown some activity in patients with HRPC, especially when the decrease in PSA has been used as a response marker. Among the most commonly used classic cytostatic are the vinca alkaloids (vinblastine, vinorelbine), cyclophosphamide and the anthracyclines (adriamycin, epirubicin, mitoxantrone). The combination of mitoxantrone with corticosteroids has been widely used in patients with HRPC due to the results of two randomized studies published in the second half of the last decade. In both studies, the combination of mitoxantrone with prednisone or hydrocortisone showed a significant benefit in the palliation of symptoms and at the PSA level, although without improving survival, compared to treatment with corticosteroids. A third randomized study confirms that the mean survival in patients treated with mitoxantrone and prednisone does not exceed 12 months, as in previous studies. Until now, the combination of mitoxantrone and corticosteroids has been considered the standard treatment in patients with HRPC.

Single agent estramustine phosphate has low activity in HRPC, however, its action on microtubules makes its activity synergistic with other cytostatic such as vinca alkaloids, etoposide and taxanes. The combination of these cytostatic with estramustine phosphate has shown a high percentage of responses by PSA, higher than $50 \%$ in many of the published studies, with a high percentage of responses in patients with measurable lesions and a mean survival greater than 12 months in some of them. However, these data have been obtained in phase II studies, sometimes with a small number of patients and, therefore, can be questionable.

In recent years, the activity of taxanes (paclitaxel and docetaxel) in the CPHR has attracted special attention. Studies in prostate cancer cell lines have demonstrated the ability of paclitaxel to reverse the resistance induced by overexpression of the bcl-2 gene. In clinical practice, the combination of paclitaxel with other drugs, especially estramustine phosphate, has shown relevant activity with a PSA response rate greater than $50 \%$ and a

\section{mean survival between 13 and 17 months.}

Recently, several studies have analyzed the activity of docetaxel in regimens of administration every 21 days or weekly. Both schemes show a high percentage of responses by PSA. In the phase II study by Savaresse et al., 47 patients with HRPC were treated with docetaxel $\left(70 \mathrm{mg} / \mathrm{m}^{2}\right.$ every 21 days), estramustine, and hydrocortisone. The PSA response rate was 69\%, with a measurable lesion response rate of $50 \%$ (12 of 24 patients) and a mean survival of 20 months. The combination of estramustine with docetaxel appears to increase the efficacy of docetaxel. In a recent randomized phase II study, the combination of docetaxel / estramustine shows a benefit in terms of PSA responses and progression-free survival compared to treatment with docetaxel, although the impact it may have on survival has not been established.

The benefit of docetaxel-based regimens has been confirmed in two recent phase III studies published in October 2004, which show that docetaxel regimens provide significant benefit in survival compared to the standard regimen with mitoxantrone and prednisone. In the Southwest Oncology Group study 9916, 674 patients with metastatic HRPC were randomized to receive docetaxel (60mg / $\mathrm{m}^{2}$ day 2), and estramustine phosphate (280mg po, days $1-5$ ) or mitoxantrone (12mg / $\mathrm{m}^{2}$ every 21 days) and prednisone (5mg PO daily). After the first cycle of treatment, the doses of docetaxel and mitoxantrone were increased to $70 \mathrm{mg} / \mathrm{m}^{2}$ and $14 \mathrm{mg} / \mathrm{m}^{2}$ in patients who did not present grade 3-4 toxicity. $90 \%$ of the patients had a good general condition (PS 0-1), and in around $20 \%$ of cases, tumor progression was established solely by increases in PSA.

In patients treated with docetaxel / estramustine, a significant increase in episodes of neutropenic fever, cardiovascular toxicity, nausea, metabolic disturbances and neurotoxicity was observed. The biochemical response rate for PSA was significantly higher in the docetaxel scheme ( $50 \%$ vs. $27 \%, \mathrm{p}<0.0001$ ). Progression-free survival was 6.3 months in the docetaxel arm compared to 3.2 months in the mitoxantrone regimen $(\mathrm{p}<0.001)$. Median survival was 17.5 months in patients treated with docetaxel / estramustine and 15.6 months in patients treated with mitoxantrone / prednisone $(\mathrm{p}=0.02)$.

In the second TAX 327 study, 1006 patients with metastatic HRPC were randomized to receive docetaxel $75 \mathrm{mg} / \mathrm{m} 2$ every 21 days vs. docetaxel weekly $\left(30 \mathrm{mg} / \mathrm{m}^{2}\right.$ weekly in cycles of 5 doses every 6 weeks) vs. the standard mitoxantrone regimen $\left(12 \mathrm{mg} / \mathrm{m}^{2}\right.$ every 21 days). In the 3 schemes prednisone was administered at a dose of $5 \mathrm{mg} 2 \mathrm{x}$ day. The duration of treatment in the $3 \mathrm{arms}$ was 30 weeks

The characteristics of the patients were similar to the SWOG 9916 study, more than $90 \%$ of patients received 2 or more hormonal treatments. The most relevant toxicity was grade $3-4$ neutropenia present in $32 \%, 1.5 \%$, and $22 \%$ of patients treated 
with docetaxel every 3 weeks, weekly docetaxel, and mitoxantrone, respectively. Non-hematological toxicity was significantly higher in the patients treated with docetaxel, although the incidence of grade 3-4 toxicity was less than $5 \%$ in the 3 treatment arms.

The PSA response rate was significantly higher in the docetaxel-treated patients, although the objective response rate in measurable lesions was similar with all three regimens. Especially relevant is the fact of the significant improvement in pain control, and in the quality of life observed in the patients treated with the two schemes with docetaxel. The mean survival of patients with docetaxel was significantly higher than that observed in patients treated with mitoxantrone ( $p=0.03$, Hazard Ratio: 0.83 ). These differences were especially significant with the docetaxel scheme every 21 weeks ( 18.9 vs 16.5 months, $p=0.009$ ), on the contrary, the differences with weekly docetaxel did not reach statistical significance (17.4 vs 16.5 months, $\mathrm{p}=0.36$ ). Patients with visceral involvement, anemia, elevated alkaline phosphatase levels, and undifferentiated tumors (Gleason 8-10) had a worse prognosis.

These studies demonstrate that docetaxel-based regimens significantly improve survival over mitoxantrone / prednisone and should be considered the standard of care in advanced HRPC. The differences are statistically significant despite the fact that the mean survival obtained in these studies with mitoxantrone / prednisone (around 16 months) is higher than that obtained in the previous randomized studies (12 months). This fact may be due to the fact that a significant percentage of patients treated with mitoxantrone received docetaxel after progression $(20 \%$ of patients in the TAX 327 study), also the characteristics of the patients may be more unfavorable in previous studies, for example, the mean baseline PSA levels were higher in the Kantoff et al study compared to current studies. Regarding toxicity, although the schemes with docetaxel are associated with a higher incidence of adverse effects, the percentages of grade 3-4 toxicity are acceptable. Other points of interest raised by these studies are: The weekly docetaxel regimen, despite significantly increasing the percentage of responses by PSA, does not improve survival compared to mitoxantrone / prednisone treatment and, therefore, cannot be considered an alternative treatment to the docetaxel regimen every 21 days, despite to present a better hematological toxicity profile.

Treatment with estramustine does not appear to provide a benefit to the combination with docetaxel over treatment with prednisone (mean survival of 17.6 months with docetaxel / estramustine and 18.9 months with docetaxel / prednisone). This fact is especially relevant, if one takes into account that patients treated with estramustine have a $7 \%$ risk of presenting thromboembolic processes. Therefore, it is necessary to seek more active treatments to combine with docetaxel).

\section{Actual state}

Today, men with prostate cancers that continue to progress despite initial hormone therapy have many more treatment options than they did a few years ago. If an antiandrogen was not part of the initial hormone therapy, it is often added at this time. In case the patient is receiving an antiandrogen, but the cancer continues to grow, stopping the antiandrogen (while continuing other hormonal treatments) sometimes seems to help.

Other forms of hormone therapy may also be helpful for a time, especially if the cancer is causing few or no symptoms. These include: abiraterone, enzalutamide, apalutamide, darolutamide, ketoconazole, estrogens (female hormones), and corticosteroids. The prostate cancer vaccine, sipuleucel-T (Provenge), is another option for men whose cancer is causing few or no symptoms. This treatment may not lower PSA levels, but it can often help patients live longer.

For cancers that are no longer responding to initial hormone therapy and that are causing symptoms, there may be several options available. Chemotherapy with the drug docetaxel (Taxotere) is often the first choice because it has been shown to help men live longer as well as reduce pain. If docetaxel does not work well or stops working, other chemotherapy drugs, such as cabazitaxel may help. Pembrolizumab immunotherapy may also be an option after chemotherapy if the cancer is MSI-H or dMMR. Another option may be a different type of hormone therapy, such as abiraterone or enzalutamide or apalutamide (if they have not already been treated). Bisphosphonates or denosumab can often help if the cancer has spread to the bones. These drugs can reduce pain and even slow cancer growth in many men. Other medications and methods can also help keep pain and other symptoms under control. External radiation therapy can help treat bone pain if it is only present in a few places. Radiopharmaceuticals can often reduce pain if it is more widespread, and they can also slow cancer growth.

Be sure to tell your doctor and your healthcare team if you experience pain caused by prostate cancer.

Several promising new drugs are currently being tested against prostate cancer, including vaccines, monoclonal antibodies, and other newer types of drugs. Because the ability to treat hormonerefractory prostate cancer is not yet effective enough, men are encouraged to participate in clinical trials to explore new options.

\section{Active surveillance for prostate cancer}

Most men diagnosed with prostate cancer have localized cancer, meaning that the cancer has not spread outside the prostate. Some men with localized prostate cancer choose active surveillance, which allows them to avoid or delay having surgery or radiation. Active surveillance is an option for men with a cancer that is very unlikely to progress or metastasize. The tests will indicate if the cancer is likely to be aggressive.

With localized prostate cancer Low-risk cancer has a very low chance of advancing immediately. These men may opt for active surveillance. This means that regular check-ups and testing will be needed to see if it progresses. This option allows a man to delay 
surgery or radiation therapy, often for many years. If the cancer grows very slowly, treatment may never be needed. Intermediaterisk cancer is more likely to grow. Some men with this type of cancer may be able to choose active surveillance. Others may have to choose surgery or radiation therapy. High-risk cancer has a high chance of metastasizing. Men with high-risk cancer may have to choose between surgery or radiation. Whether or not active surveillance is a good option is something that will usually have to be discussed with the oncologist.

\section{Factors to Consider (Risk Factors)}

a) Life expectancy.

b) The stage and Gleason score of your cancer

c) General health status.

d) Possible side affects you might have from other treatments.

e) Personal preferences should be part of this decision.

With active surveillance, clinical follow-up is done. During this time, you will be monitored and tested, such as PSA tests, digital rectal exam and prostate biopsies. It may seem strange to have cancer and not have surgery to remove it or not have radiation therapy to remove the cancer. But, unlike many other types of cancer, most prostate cancers grow very slowly. Slow-growing prostate cancer usually does not cause symptoms. Therefore, it is possible to have prostate cancer for years without knowing it. Prostate cancer treatments such as surgery and radiation have serious side effects. These side effects include bladder, bowel and erection problems. With active surveillance, men can wait before starting other treatments. Some men will never need more treatment. And others may delay treatment until evidence shows that the cancer is growing faster.

Regular checkups will show if the cancer is progressing. And if it does, the cancer can still be treated in the early stages, when treatments are most successful.

\section{What to expect after treatment?}

Active surveillance sometimes continues for years. In other cases, there comes a time when evidence indicates that the cancer is growing and needs to be treated.

\section{Why it is done}

Prostate cancer is usually a slow-growing type of cancer. About 12 out of every 100 men in Argentina will have prostate cancer. But most men who are diagnosed with prostate cancer do not die from it.

\section{Effectiveness}

Men with localized prostate cancer who have a low probability of their cancer spreading can opt for active surveillance. One study compared active observation (a wait-and-see program like active surveillance), surgery, and radiation in men with localized prostate cancer and found that the risk of dying was very low and about the same, regardless of the alternative the men chose. Another study examined men with low-risk localized prostate cancer (and some men with intermediate-risk prostate cancer) and found that At 5 years, approximately 76 of every 100 men were not treated and were still on active surveillance. At 10 years, approximately 64 men out of 100 did not receive treatment and were still on active surveillance. At age 15, approximately 55 of every 100 men were not treated and were still on active surveillance.

\section{Risks}

Prostate cancer is likely to grow during active surveillance. If this happens, treatment, such as surgery or radiation, must be indicated. If the patient chooses active surveillance, it is very important to follow the schedule of tests and exams. Regular checkups will increase the chances of knowing right away if the prostate cancer grows. That way, the cancer can still be treated in the early stages, when treatments are most successful.

\section{Conclusion}

At present, regimens based on docetaxel plus enzalutamide or with abiraterone are the gold standard in advanced HRPC. These regimens obtain around 50\% responses by PSA, a progressionfree survival of 6 months, and a mean survival of 18 months. The positive impact on survival of the docetaxel regimens is accompanied by an improvement in pain control and in the quality of life of the patients compared to the classical treatment with mitoxantrone / prednisone.

New cytostatic (epothilones) have shown activity in HRPC, even in patients previously treated with taxanes.

New agents that act on specific targets show promising activity, especially in combination with cytostatic.

Better knowledge of the genetic alterations involved in the development of hormone-resistant prostate cancer may allow the selection of the most appropriate treatment for each patient.

\section{References}

1. Hull GW, Rabbani F, Abbus F, Wheeler TM, Kattan MW, et al. (2002) Cancer control with radical prostatectomy alone in 1000 consecutive patients. J Urol No. 167(2): 528-534.

2. Huñis AP (2016) A current view of oncology in Argentina. ecancer.

3. Huñis AP (2008) Introduction to Clinical Oncology. Prostate cancer. chap. 21 Editorial UNQ pp. 619-651.

4. Huñis AP. Advances in the diagnosis and treatment of prostate cancer Abbot Laboratories Argentina S.A. pp, 1-17.

5. Quinlan DM, Epstein JI, Carter BS, Walsh PC (1991) Sexual function following radical prostatectomy: influence of preservation of neurovascular bundles. J Urol No 145(5): 998-1002.

6. Shipley WU, Thames HD, Sandler HM, Hanks GE, Zietman AL, et al. (1999) Radiation therapy for clinically localized prostate cancer: a multi-institutional pooled analysis. JAMA 281(17): 1598-1604. 


\section{Cancer Therapy \& Oncology International Journal}

7. Pollack A, Zagars GK, Smith LG, Lee JJ, von Eschenbach AC, et al. (2000) Preliminary results of a randomized radiotherapy dose-escalation study comparing 70 Gy with 78 Gy for prostate cancer. J Clin Oncol No. 18(23): 3904-3911.

8. Yock TI, Zietman AL, Shipley WU, Thakral HK, Coen JJ (2002) Long-term durability of PSA failure-free survival after radiotherapy for localized prostate cancer. Int J Radiat Oncol Biol Phys No. 54(2): 420-426.

9. Fowler FJ, McNaughton CM, Albertsen PC, Zietman AL, Elliott DB, et al. (2000) Comparison of recommendations by urologists and radiation oncologists for treatment of clinically localized prostate cancer. JAMA 283(24): 3217-3222.

10. Sands ME, Pollack A, Zagars GK (1995) Influence of radiotherapy on node-positive prostate cancer treated with androgen ablation. Int Radiat Oncol Biol Phys 31(1): 13-19.

11. Tannock IF, Osoba D, Stockler MR, Ernst DS, Neville AJ, et al. (1996) Chemotherapy with mitoxantrone plus prednisone or prednisone alone for symptomatic hormone-resistant prostate cancer: a Canadian randomized trial with palliative end points. J Clin Oncol N 14(6): 17561764.

12. Petrylak DP, Macarthur RB, Connor JO, Shelton G, Judge T, et al. (1999) Phase I trial of docetaxel with estramustine in androgen-independent prostate cancer. J Clin Oncol No 17(3): 958-967.

13. Messing EM, Manola J, Sarosdy M, Wilding G, Crawforf ED, et al. (1999) Immediate hormonal therapy compared with observation after radical prostatectomy and pelvic lymphadenectomy in men with node positive prostate cancer. N Eng J Med No. 341(24): 1781-1788.

14. Huggins C, Hodges CV (1941) Studies on prostatic cancer, effect of castration, of estrogen and of androgen injection on serum phosphatases in metastatic carcinoma of the prostate. Cancer Res 1(4): 293-297.

15. Feldman BJ, Feldman D (2001) The development of androgen independent prostate cancer. Nature Rev Cancer 1(1): 34-45.

16. Scher HI, Liebertz C, Kelly WK (1997) Bicalutamide for advanced prostate cancer: the natural vs the treated history of disease. J Clin Oncol 15(8): 2928-2938.

17. Goldenberg SL, Bruchovsky N, Rennie PS, Coppin CM (1988) The combination of cyproterone acetate and low dose diethylstilbestrol in the treatment of advanced prostatic carcinoma. J Urol 140(6): 14601465.

18. Keller ET, Zhang J, Cooper C (2001) Prostate carcinoma skeletal metastases: crosstalk between tumor and bone. Cancer Metastasis Rev 20(3-4): 333-349.

19. Labrie F, Dupont A, Belanger A, Lacoursiere Y, Raynaud JP, et al. (1983) New approach in the treatment of prostate cancer: complete instead of partial withdrawal of androgens. Prostate 4(6): 579-594.

20. Schmitt B, Bennett C, Seidenfeld J, Samson D, Wilt T (2000) Maximum androgen blockade for advanced prostate cancer (Cochrane Review). In: Cochrane Database Syst Rev 2, CD001526.

21. Carducci MA, Padley RJ, Breul J, Nicholas JV, Bernard AZ, et al. (2003) Effect of endothelin-a receptor blockade with atrasentan on tumor progression in men with hormone-refractory prostate cancer: a randomized phase II, placebo-controlled trial. J Clin Oncol 21(4): 679689

22. Scher H, Heller G (2000) Clinical States in prostate cancer: toward a dynamic model of disease progression. Urology 55(3): 323-337.

23. Eisenberger MA, Crawford ED, Wolf M, Blumenstein BA, McLeod DG, et al. (1998) Bilateral orchiectomy with or without flutamide for metastatic prostate cancer. N Eng J Med 339(15): 1036-1042.
24. American Society of Clinical Oncology (2004) Recommendations for the initial hormonal management of androgen-sensitive-metastatic, recurrent, or progressive prostate cancer. J Clin Oncol 22: 2927-2941.

25. Damico AV, Chen M, Roehl KA, Catalona WJ (2004) Preoperative PSA velocity and the risk of death from prostate cancer alter radical prostatectomy. N Eng J Med 351(2): 125-135.

26. Gleason DF (1966) Classification of prostatic carcinomas. Cancer Chemother Rep 50(3): 125-128.

27. Murphy GP, Busch C, Abrahamsson PA, Epstein JI, McNeal JE, et al. (1993) Histopathology of localized prostate cancer. Consensus Conference on Diagnosis and Prognostic Parameters in Localized Prostate Cancer. Stockholm, Sweden, May 12-13, 1993. Scand J Urol Nephrol Suppl 162: 7-42.

28. Epstein JI, Allsbrook WC, Amin MB, Egevad LL (2005) ISUP Grading Committee. The 2005 International Society of Urological Pathology (ISUP) consensus conference on Gleason grading of prostatic carcinoma. Am J Surg Pathol 29(9): 1228-1242.

29. Pierorazio PM, Walsh PC, Partin AW, Epstein JL (2013) Prognostic Gleason grade grouping data based on the modified Gleason scoring system. BJU Int 111(5): 753-760.

30. Epstein JI, Egevad L, Amin MB, Delahunt B, Srigley JR, et al. (2016) The 2014 International Society of Urological Pathology (ISUP) consensus conference on Gleason grading of prostatic carcinoma. Am J Surg Pathol 40(2): 244-252.

31. Zietman A, Smith J, Klein E, Droller M, Dasgupta P, et al. (2016) Reply to letter to editor about new Gleason grading system: Statement from the editors of six journals [letter]. Urol Oncol 34(11): 481.

32. Epstein JI (2016) Prostate cancer grading: a contemporary photomontage [letter]. Am J Surg Pathol 40(1): 137-138.

33. Delahunt B, Egevad L, Grignon DJ, Srigley JR, Sasmaratunga H (2016) Prostate cancer grading: recent developments and future directions. BJU Int 117 Suppl 4: 7-8.

34. Partin AW, Kattan MW, Subong EN, Walsh PC, Wojno KJ, et al. (1997) Combination of prostate-specific antigen, clinical stage, and Gleason score to predict pathological stage of localized prostate cancer. JAMA 277(18): 1445-1451.

35. Eifler JB, Feng Z, Lin B, Partin MT, Humphreys EB, et al. (2013) An updated prostate cancer staging nomogram (Partin Tables) based on cases from 2006-2011. BJU 111(1): 22-29.

36. Epstein JI (2000) Gleason score 2-4 adenocarcinoma of the prostate on needle biopsy: a diagnosis that should not be made. Am J Surg Pathol 24(4): 477-478.

37. Miyamoto H, Hernandez DJ, Epstein JI (2009) A pathological reassessment of organ-confined, Gleason score 6 prostatic adenocarcinomas that progress after radical prostatectomy. Hum Pathol 40(12): 1693-1698.

38. Haffner MC, Mosbruger T, Esopi DM, Fedor H, Heaphy CM, et al. (2013) Tracking the clonal origin of lethal prostate cancer. J Clin Invest 123(11): 4918-4922.

39. Epstein JI, Feng Z, Trock BJ, Pierorazio PM (2012) Upgrading and downgrading of prostate cancer from biopsy to radical prostatectomy: Incidence and predictive factors using the modified Gleason Grading system and factoring in tertiary grades. Eur Urol 61(5): 1019-1024.

40. Howlader N, Noone AM, Krapcho M (2017) SEER Cancer Statistics Review, 1975-2014. Bethesda, MD: Natl. Cancer Inst, Based on the November 2016 SEER data submission, published on the SEER website in April. 


\section{Cancer Therapy \& Oncology International Journal}

41. Scher HI, Halabi S, Tannock I (2008) Design and endpoints of clinical trials for patients with progressive prostate cancer and castration levels of testosterone: recommendations of the Prostate Cancer Clinical Trials Task Force. J Clin Oncol 26: 1148-1159.

42. Scher HI, Morris MJ, Stadler WM (2016) Trial Design and Goals for Castration-Resistant Prostate Cancer: Updated Recommendations from the Prostate Cancer Clinical Trials Task Force 3. J Clin Oncol 34: 1402-1418.

43. Huggins C (1942) Effect of orchiectomy and irradiation on prostate cancer. Ann Surg 115(6): 1192-1200.

44. Huggins C (1944) The treatment of prostate cancer: the 1943 speech in surgery before the Royal College of Physicians and Surgeons of Canada. Power. Medicine. Assoc J 50: 301-307.

45. Caubet JF, Tosteson TD, Dong EW, Naylon EM, Whiting GW, et al. (1997) Maximal androgen blockade in advanced prostate cancer: a metaanalysis of published randomized controlled trials using nonsteroidal antiandrogens. Urology 49: 71-78.

46. Small EJ, Halabi S, Dawson NA (2004) Withdrawal from antiandrogens alone or in combination with ketoconazole in patients with androgenindependent prostate cancer: a phase III trial (CALGB 9583). J Clin Oncol 22: 1025-1033.

47. Tannock I, Gospodarowicz M, Meakin W, Panzarella T, Stewart L, et al. (1989) Treatment of metastatic prostate cancer with low-dose prednisone: assessment of pain and quality of life as pragmatic indices of response. J Clin Oncol 7(5): 590-597.

48. Tannock IF, Osoba D, Stockler MR, Ernst DS, Neville AJ, et al. (1996) Chemotherapy with mitoxantrone plus prednisone or prednisone alone for symptomatic hormone-resistant prostate cancer: a Canadian randomized trial with palliative endpoints. J Clin. Oncol 14(6): 1756 1764.

49. Kantoff PW, Halabi S, Conaway M, Picus J, Kirshner J, et al. (1999) Hydrocortisone with or without mitoxantrone in men with hormone refractory prostate cancer: results of the cancer and leukemia group B 9182 study. J Clin Oncol 17(8): 2506-2513.

50. Petrylak DP, Tangen CM, Hussain MH, Primo NL, Jeffrey AJ, et al (2004) Docetaxel and estramustine compared with mitoxantrone and prednisone for advanced refractory prostate cancer. N Engl J Med 351(15): 1513-1520.

51. Tannock IF, de Wit R, Berry WR, Jozsef H, Anna P, et al. (2004) Docetaxel plus prednisone or mitoxantrone plus prednisone for advanced prostate cancer. N Engl J Med 351(15): 1502-1512.

52. De Bono JS, Oudard S, Ozguroglu M, Steinbjørn H, Jean PM, et al. (2010) Prednisone plus cabazitaxel or mitoxantrone for castration-resistant metastatic prostate cancer that progresses after treatment with docetaxel: a randomized open-label trial. Lancet 376(9747): 11471154 .

53. Kantoff PW, Higano CS, Shore ND, Berger RE, Eric JS, et al. (2010) Sipuleucel-T immunotherapy for castration-resistant prostate cancer N Engl J Med 363(5): 411-422.

54. Parker C, Nilsson S, Heinrich D (2013) Radium-223 alpha emitter and survival in metastatic prostate cancer. N Engl J Med 369: 213-223.

55. Smith MR, Saad F, Chowdhury S, Stéphane O, Boris AH, et al. (2018) Apalutamide treatment and metastasis-free survival in prostate cancer. N Engl J Med 378(15): 1408-1418.

56. Scher HI, Fizazi K, Saad F, Mary ET, Cora NS, et al. (2012) Increased survival with enzalutamide in prostate cancer after chemotherapy. N Engl J Med 367(13): 1187-1197.

57. Beer TM, Armstrong AJ, Rathkopf D, Yohann L, Sternberg CN, et al. (2014) Enzalutamide in metastatic prostate cancer before chemotherapy. N Engl J Med 371(15): 424-433.

58. James ND, de Bono JS, Spears MR, Noel WC, Malcolm DM, et al. (2017) Abiraterone for prostate cancer not previously treated with hormone therapy. N Engl J Med 377(4): 338-351.

59. Fizazi K, Tran N, Fein L (2017) Abiraterone plus prednisone in castration-sensitive metastatic prostate cancer. N Engl J Med 377: 352360 .

60. Mateo J, Carreira S, Sandhu S, Susana M, Helen M, et al. (2015) DNA repair defects and olaparib in metastatic prostate cancer. N Engl J Med 373: 1697-1708.

61. Eisenberger M, Hardy BAC, Kim CS, Lajos G, Daniel F, et al. (2017) Phase III study comparing a reduced dose of cabazitaxel $\left(20 \mathrm{mg} / \mathrm{m}^{2}\right)$ and the currently approved dose $\left(25 \mathrm{mg} / \mathrm{m}^{2}\right)$ in post-docetaxel patients with castration-resistant metastatic prostate cancer: PROSELICA. J Clin Oncol 35(28): 3198-3206.

62. Oudard S, Fizazi K, Sengelov L, Gedske D, Fred S, et al. (2017) Cabazitaxel versus docetaxel as first-line therapy for patients with castration-resistant metastatic prostate cancer: a randomized phase III trial - FIRSTANA. J Clin Oncol 35(28): 3189-3197.

63. Antonarakis ES, Tagawa ST, Galletti G (2017) Non-comparative, randomized phase II trial of early switch from docetaxel to cabazitaxel or vice versa, with integrated biomarker analysis, in men with castration-resistant, metastatic, and chemotherapy-free prostate cancer. J Clin Oncol 35: 3181-3188.

64. Attard G, Reid AH, Yap TA (2008) Phase I clinical trial of a selective CYP17 inhibitor, abiraterone acetate, confirms that castration-resistant prostate cancer is normally still driven by hormones. J Clin Oncol 26: 4563-4571.

65. De Bono JS, Logothetis CJ, Molina A, Luis C, Kim NC, et al. (2011) Abiraterone and increased survival in metastatic prostate cancer. $\mathrm{N}$ Engl J Med 364(21): 1995-2005.

66. Ryan CJ, Smith MR, De Bono JS (2013) Abiraterone in metastatic prostate cancer without prior chemotherapy. N Engl J Med 368: 138148.

67. Ryan CJ, Smith MR, Fizazi K (2015) Abiraterone acetate plus prednisone versus placebo plus prednisone in chemotherapy-naïve men with castration-resistant metastatic prostate cancer (COU-AA-302): final overall survival analysis of a randomized, double-blind, controlled phase 3 study with placebo. Lancet Oncol 16: 152-160.

68. Tran C, Ouk S, Clegg NJ, Chen Y, Philip AW, et al. (2009) Development of a second-generation antiandrogen for the treatment of advanced prostate cancer. Science 324(5928): 787-790.

69. Collins C, Eary JF, Donaldson G, Bush NE, Petersdorf S, et al. (1993) Samarium-153-EDTMP in bone metastases from hormone-refractory prostate carcinoma: a phase I / II trial. J Nucl Med 34(11): 1839-1844.

70. Sartor O, Reid RH, Hoskin PJ, Donald PQ, Peter JE, et al. (2004) Samarium-153-lexidronam complex for the treatment of painful bone metastases in hormone-refractory prostate cancer. Urology 63(5): 940-945.

71. James ND, Pirrie SJ, Pope AM, Darren B, Lazaros A, et al. (2016) Clinical Outcomes and Survival After Treatment of Metastatic CastrationRefractory Prostate Cancer with Docetaxel Alone or Strontium-89, Zoledronic Acid, or Both: Trapeze Randomized Clinical Trial. JAMA Oncol 2(4): 493-499.

72. Oosterhof GO, Roberts JT, De Reijke TM, Horenblas S, Von Der MH, et al (2003) Strontium chloride 89 versus palliative local field radiotherapy in patients with hormonal escaped prostate cancer: a phase III study of the European Organization for Research and Treatment of Cancer Genitourinary Group. EUR. Urol 44(5): 519-526. 


\section{Cancer Therapy \& Oncology International Journal}

73. Nilsson S, Franzen L, Parker C (2007) Radio-223 targeting bone in symptomatic and hormone-refractory prostate cancer: a randomized, multicenter, placebo-controlled phase II study. Lancet Oncol 8: 587594.

74. Nilsson S, Strang P, Aksnes AK (2012) A multicenter, randomized, doseresponse phase II study of radium-223 chloride for the palliation of painful bone metastases in patients with castration-resistant prostate cancer. EUR. J Cancer 48: 678-686.

75. Mirski D (2017) Xofigo ${ }^{\circledR}$ (radium Ra 223 dichloride): major update to safety information regarding increased incidence of deaths and fractures in a phase III research clinical trial with Xofigo used in combination with acetate abiraterone and prednisolone / prednisone. Bayer Important Drug Warning.

76. Small EJ, Schellhammer PF, Higano CS (2006) Phase III, placebocontrolled trial of immune therapy with sipuleucel-T (APC8015) in patients with metastatic, asymptomatic, hormone-refractory prostate cancer. J Clin Oncol 24: 3089-3094.

77. George DJ, Nabhan C, DeVries T (2015) Survival results of phase III studies of sipuleucel-T: impact of crossing the control arm with salvage immunotherapy. Cancer Immunol Res 3: 1063-1069.

78. Higano CS, Schellhammer PF, Small EJ, Patrick AB, John N, et al. (2009) Integrated data from 2 randomized, double-blind, placebo-controlled phase 3 trials of active cellular immunotherapy with sipuleucel-T in advanced prostate cancer. Cancer 115(6): 3670-3679.

79. Pritchard CC, Mateo J, Walsh MF (2016) Hereditary DNA repair gene mutations in men with metastatic prostate cancer. N Engl J Med 375: 443-453.

80. Abida W, Armenia J, Gopalan A (2017) The prospective genomic profile of prostate cancer in all disease states reveals somatic and germline alterations that can affect clinical decision-making. J Clin Oncol Precision Oncol.

81. Beer TM, Kwon ED, Drake CG (2017) Randomized, double-blind phase III trial of ipilimumab versus placebo in asymptomatic or minimally symptomatic patients with castration-resistant metastatic prostate cancer without prior chemotherapy. J Clin Oncol 35: 40-47.

82. Kwon ED, Drake CG, Scher HI (2014) Ipilimumab versus placebo after radiotherapy in patients with castration-resistant metastatic prostate cancer that had progressed after chemotherapy with docetaxel (CA184-043): a multicenter, randomized, double-blind phase 3 trial. Lancet Oncol 15(7): 700-712.

83. Topalian SL, Hodi FS, Brahmer JR, Scott NG, David CS, et al. (2012) Safety, activity and immunological correlates of anti-PD-1 antibody in cancer. N Engl J Med 366(26): 2443-2454.

84. Patnaik A, Kang SP, Rasco D, Kyriakos PP, Jeroen ES, et al. (2015) Phase I study of pembrolizumab (MK-3475; anti-PD-1 monoclonal antibody) in patients with advanced solid tumors. Clin Cancer Res 21(19): 42864293.

85. Graff JN, Alumkal JJ, Drake CG, George VT, William LR, et al. (2016) Early evidence of anti-PD-1 activity in enzalutamide-resistant prostate cancer. Oncotarget 7(33): 52810-52817.

86. De Bono JS, Goh JCH, Ojamaa K, Jose MPR, Charles G, et al. (2018) KEYNOTE-199: Pembrolizumab (pembro) for docetaxel-resistant castration-resistant metastatic prostate cancer (mCRPC). J Clin Oncol 36(15): 5007

87. Le DT, Durham JN, Smith KN, Hao W, Bjarne RB, et al. (2017) Mismatch repair deficiency predicts the response of solid tumors to PD-1 blockade. Science 357(6349): 409-413.

88. Pritchard CC, Morrissey C, Kumar A (2014) Complex MSH2 and MSH6 mutations in unstable advanced prostate cancer with hypermuted microsatellites. Nat Commun 25: 4988.

89. Abida W, Cheng ML, Amernia J (2018) Instability of microsatellites in prostate cancer and response to blocking of immune checkpoints. J Clin Oncol 36: 5020.

90. Wu YM, Cieslik M, Lonigro RJ (2018) CDK12 inactivation delineates a distinct immunogenic class of advanced prostate cancer. Cell 173: 170182.

91. Annala M, Vandekerkhove G, Khalaf D (2018) Genomics of circulating tumor DNA correlates with resistance to abiraterone and enzalutamide in prostate cancer. Cancer Discov 8: 444-457.

92. Sundi D, Wang VM, Pierorazio PM (2014) Very high risk localized prostate cancer: definition and results. Prostatic prostate cancer. Dis 17: 57-63.

93. Antonarakis ES, Feng Z, Trock BJ, Elizabeth BH, Michael AC, et al. (2012) The natural history of metastatic progression in men with prostate-specific antigen recurrence after radical prostatectomy: longterm follow-up. BJU Int 109(1): 32-39.

94. Pound CR, Partin AW, Eisenberger MA (1999) Natural history of progression after PSA elevation after radical prostatectomy. JAMA 281(17): 1591-1597.

95. Crook JM, Callaghan OCJ, Duncan G (2012) Intermittent androgen suppression for increased PSA level after radiation therapy. $\mathrm{N}$ Engl J Med 367: 895-903.

96. Smith MR, Saad F, Oudard S (2013) Free survival of bone metastases and denosumab in men with non-metastatic castration-resistant prostate cancer: exploratory baseline prostate-specific antigen doubling time tests. J Clin Oncol 31: 3800-3806.

97. Hussain M, Fizazi K, Saad F, Per R, Neal S, et al. (2018) Enzalutamide in men with non-metastatic castration-resistant prostate cancer. N Engl J Med 378(26): 2465-2474

98. Xie W, Regan MM, Buyse M, Susan H, Philip WK, et al. (2017) Metastasisfree survival is a strong proxy for overall survival in localized prostate cancer. J Clin Oncol 35(27): 3097-3104.

99. Choline C (2012) 11 injection [leaflet]. Rochester, MN: Mayo Clinic.

100. (2016) AXUMIN (fluciclovine F 18) injection [package insert]. Blue Earth Diagnostics LTD, Oxford, UK.

101. Sweeney CJ, Chen YH, Carducci M, David FJ, Mario E, et al. (2015) Chemohormonal therapy in metastatic hormone-sensitive prostate cancer. N Engl J Med 373(8): 737-746.

102. Kyriakopoulos CE, Chen YH, Carducci MA, Glenn L, David FJ, et al. (2018) Chemohormonal therapy in hormone-sensitive metastatic prostate cancer: Long-term survival analysis of the randomized phase III E3805 CHAARTED trial. J Clin Oncol 36(11): 1080-1087.

103. James ND, Sydes MR, Clarke NW (2016) Addition of docetaxel, zoledronic acid, or both to long-term first-line hormonal therapy in prostate cancer (STAMPEDE): survival results from an adaptive, multi-arm, multi-stage, platform, randomized controlled trial. Lancet 387: 1163-1177.

104. Gravis G, Fizazi K, Joly F, Franck P, Benjamin E, et al. (2013) Androgen deprivation therapy alone or with docetaxel in metastatic noncastrated prostate cancer (GETUG-AFU 15): a phase 3, randomized open-label trial. Lancet Oncol. 14(2): 149-158.

105. Gravis G, Boher JM, Joly F (2015) Androgen deprivation therapy (ADT) plus docetaxel versus ADT alone in metastatic non-castrated prostate cancer: impact of metastatic burden and long-term survival analysis of the randomized phase 3 GETUG-AFU trial15. EUR. Urol 70: 256-262. 


\section{Cancer Therapy \& Oncology International Journal}

106. Sydes MR, Spears MR, Mason MD (2018) Adding Abiraterone or Docetaxel to Long-Term Hormone Therapy for Prostate Cancer: Directly Randomized Data from the Multi-arm, Multi-Stage STAMPEDE Platform Protocol. Ana Oncol 29: 1235-1248.

107. Strimbu K, Tavel JA (2010) What are biomarkers? Curr Opin HIV AIDS 5: 463-66.

108. Antonarakis ES, Lu C, Wang H, Brandon L, Mary N, et al. (2014) AR-V7 and resistance to enzalutamide and abiraterone in prostate cancer. $\mathrm{N}$ Engl J Med 371(11): 1028-1038.

109. Antonarakis ES, Lu C, Luber B (2015) Androgen receptor 7 splice variant and efficacy of taxane chemotherapy in patients with castration-resistant metastatic prostate cancer. JAMA Oncol 1: 582591.

110. Conteduca V, Wetterskog D, Sharabiani MTA, Grande E, Fernandez PMP, et al. (2017) Androgen receptor gene status in plasma DNA is associated with worse outcome with enzalutamide or abiraterone for castration-resistant prostate cancer: a multi-institution correlative biomarker study. Ana. Oncol 28(7): 1508-1516.

111. Hussain M, Daignault NS, Twardowski PW (2018) Androgen receptor targeting and DNA repair in castration-resistant metastatic prostate cancer: Results from NCI 9012. J Clin Oncol 36: 991-999.

112. Annala M, Struss WJ, Warner EW (2017) Treatment results and tumor loss of heterozygosity in germline DNA repair-deficient prostate cancer. EUR. Urol 72: 34-42.

113. Robinson D, Van Allen EM, Wu YM, Nikolaus S, Robert JL, et al. (2015) Integrative clinical genomics of advanced prostate cancer. Cell 161(5): 1215-1228

114. Aus G, Robinson D, Rosell J, Sandblom G (2005) Survival in prostate carcinoma: results of a prospective population-based cohort of 8,887 men with up to 15 years of follow-up: results from three countries in the National Registry of Population-based Swedish Prostate Cancer. Cancer 103: 943-951.

115. Heidenreich A, Pfister D, Porres D (2015) Cytoreductive radical prostatectomy in patients with prostate cancer and low-volume skeletal metastases: results of a feasibility and case-control study. J Urol 193(3): 832-838.

116. Sooriakumaran P, Karnes J, Stief C, Bethan C, Francesco M, et al. (2016) A multi-institutional analysis of perioperative outcomes in 106 men who underwent radical prostatectomy for distant metastatic prostate cancer at presentation. EUR. Urol 69(5): 788-794.
117. Antwi S, Everson TM (2014) Prognostic impact of definitive local therapy of the primary tumor in men with metastatic prostate cancer at diagnosis: a population-based propensity score analysis. Cancer Epidemiol 38(4): 435-441.

118. Culp SH, Schellhammer PF, Williams MB (2014) Could men diagnosed with metastatic prostate cancer benefit from definitive treatment of the primary tumor? A study based on SEER. EUR Urol 65: 1058-1066.

119. Rusthoven CG, Jones BL, Flaig TW, David C E, Matthew K, et al. (2016) Improved survival with prostate radiation in addition to androgen deprivation therapy for men with newly diagnosed metastatic prostate cancer. J Clin Oncol 34(24): 2835-2842.

120. Pérez López R, Lorente D, Blackledge MD (2016) The volume of bone metastases evaluated with diffusion-weighted images of the whole body is associated with overall survival in castration-resistant metastatic prostate cancer. Radiology 280: 151-160.

121. Vargas HA, Wassberg C, Fox JJ, Debra AG, Deborah K, et al. (2014) Bone metastases in castration-resistant prostate cancer: associations between CT morphological patterns, glycolytic activity, and androgen receptor expression on PET and overall survival. Radiology 271(1): 220-229.

122. Pasqualetti F, Panichi M, Sainato A, Fabrizio M, Luca G, et al. (2016) [18 F] Choline PET / CT and stereotactic body radiotherapy in the treatment decision-making of patients with oligometastatic prostate cancer: preliminary results. Radiat Oncol. 11: 9.

123. Decaestecker K, De Meerleer G, Lambert B (2014) Repeat stereotaxic body radiation therapy for recurrence of oligometastatic prostate cancer. Radiat Oncol 9: 135.

124. Ost P, Jereczek Fossa BA, As NV (2016) Progression-free survival after stereotactic body radiation therapy for treatment-naïve recurrence of oligometastatic prostate cancer: a multi-institutional analysis. EUR. Urol 69: 9-12.

125. Ost P, Reynders D, Decaestecker K (2018) Surveillance or metastasisdirected therapy for recurrence of oligometastatic prostate cancer: a prospective, randomized, multicenter phase II trial. J Clin Oncol 36: 446-453.

126. Shaughnessy MJO, McBride SM, Vargas HA, Karim AT, Michael JM, et al. (2016) A pilot study of a multimodal treatment paradigm to accelerate drug evaluations in early-stage metastatic prostate cancer. Urology 102: 164-172.

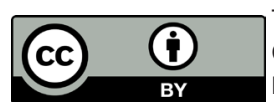

This work is licensed under Creative Commons Attribution 4.0 License DOI:10.19080/CTOIJ.2020.17.555972
Your next submission with Juniper Publishers will reach you the below assets

- Quality Editorial service

- Swift Peer Review

- Reprints availability

- E-prints Service

- Manuscript Podcast for convenient understanding

- Global attainment for your research

- Manuscript accessibility in different formats

(Pdf, E-pub, Full Text, Audio)

- Unceasing customer service

Track the below URL for one-step submission https://juniperpublishers.com/online-submission.php 